Notre Dame Journal of Formal Logic

Volume 41, Number 3, 2000

\title{
FREGE ON AXIOMS, INDIRECT PROOF, AND INDEPENDENCE ARGUMENTS IN GEOMETRY: DID FREGE REJECT INDEPENDENCE ARGUMENTS?
}

\author{
JAMIE TAPPENDEN
}

\begin{abstract}
It is widely believed that some puzzling and provocative remarks that Frege makes in his late writings indicate he rejected independence arguments in geometry, particularly arguments for the independence of the parallels axiom. I show that this is mistaken: Frege distinguished two approaches to independence arguments and his puzzling remarks apply only to one of them. Not only did Frege not reject independence arguments across the board, but also he had an interesting positive proposal about the logical structure of correct independence arguments, deriving from the geometrical principle of duality and the associated idea of substitution invariance. The discussion also serves as a useful focal point for independently interesting details of Frege's mathematical environment. This feeds into a currently active scholarly debate because Frege's supposed attitude to independence arguments has been taken to support a widely accepted thesis (proposed by Ricketts among others) concerning Frege's attitude toward metatheory in general. I show that this thesis gains no support from Frege's puzzling remarks about independence arguments.
\end{abstract}

\section{Introduction}

One of the more puzzling episodes in Frege's history is his joust with Hilbert and Korselt on the foundations of geometry. On the surface, Frege just seems cranky and dense. He makes no effort to interpret Hilbert charitably, not even to serve the dialectical function of addressing the strongest possible opponent. Many commentators have concluded that Frege is treating his audience to little more than a tiresome exercise in strawman-bashing while failing to grasp what Hilbert is up to.

It is especially puzzling that Frege sometimes writes as if he rejects independence arguments in geometry. It would be astonishing to find a trained geometer saying this

Received March 29, 2001; printed September 30, 2002

2001 Mathematics Subject Classification: Primary, 01A55; Secondary, 03-03,03A05

Keywords: geometry, independence, logic, invariance, Frege, Hilbert, duality, axiom of parallels

(C)2001 University of Notre Dame 
nearly thirty years after the work of Klein and Beltrami. Indeed, about twenty-five years earlier, Frege himself had written: "geometry . . . as surely no mathematician will doubt, requires certain axioms peculiar to it where the contrary of these axiomsconsidered from a purely logical point of view-is just as possible, i.e. is without contradiction" (Frege [24], p. 112). The question is particularly urgent to anyone interested in Frege's 1903 and 1906 "Foundations of Geometry" essays (Frege [27], [28]). If Frege rejects independence arguments in general, he must reject his positive proposals in those essays.

This paper is one of a series aimed at bringing out that the views sketched in [27] and [28] are quite interesting, with deep roots in Frege's mathematical activity and philosophical opinions tracing back even to his graduate education in the early 1870s. This installment has a narrow textual focus, arguing that the Fregean remarks that have been taken as objections to independence arguments tout court are making much more restricted points about specific ways of framing and attempting independence arguments.

In particular, one aside in a 1910 communication to Jourdain will be useful as an organizational focus. (I'll call it "the Jourdain sentence".) Frege remarks: "The unprovability of the parallel axiom cannot be proved" (Frege [23], p. 183). Quoted out of context this could be taken to indicate a general rejection of independence proofs in geometry, and on occasion it has been. This paper will argue that the remark indicates no change of position from the earlier views and should not play any significant role in our understanding of Frege's approach to the foundations of geometry.

The paper separates into a positive part clarifying what the Jourdain sentence means, and a negative part arguing that whatever Frege might mean, he does not mean to be rejecting independence arguments of the sort sketched in [28]. ${ }^{2}$ The first part, consisting of Sections $2-8$ sets out a case that in the crucial texts from the period after the composition of [28] Frege means to reject "independence arguments" in only one of two senses. Here the key is an attentive reading of Frege's post-1906 writings which reveal that Frege distinguishes two ideas of independence which are not equivalent for him. One of them informs the [28] sketch and the other is at issue in the Jourdain remarks. The negative thesis, which takes up the rest of the paper, is worth separate treatment, for two reasons. First, the Jourdain sentence is crucial for establishing Frege's attitude to independence arguments, as in the final analysis it is the only place where Frege appears to reject them. In turn this feeds into a currently active scholarly brouhaha because it has been taken to support a widely held, and I think quite implausible claim, about Frege's attitude toward metatheory. Second, the negative thesis is a useful focal point for independently interesting details of Frege's mathematical environment.

\section{Background: Frege on Geometry up to 1906 plus Two Definitions of 'Independence'}

In this section I will sketch the needed background on Frege's work on geometry and its foundations. ${ }^{3}$ Frege's engagement with ongoing geometrical work began with his $1872 \mathrm{Ph} . \mathrm{D}$. thesis on the representation of imaginary elements and continued throughout his career at Jena. He carried out serious geometrical research until at least 1906 and taught classes at all levels on geometry and bordering fields until his retirement from teaching in 1918. The relevant details of his attitudes toward geometry separate into three chronological strata: 
1. up to and for some time after Grundlagen [13] (1884),

2. sometime after the introduction of the sense-reference distinction, up to the correspondence of 1899-1900,

3. Frege's papers of 1903 and 1906.

2.1 Up to and for some time after Grundlagen (1884) From his Ph.D. thesis onward, Frege displays a cognizance of what (in his mathematical environment) were regarded as two distinct approaches to the questions bound up with independence proofs. One of these approaches-associated with Plücker and later Lie-is based on a family of techniques and theoretical observations that Frege exploits repeatedly in his geometrical research and teaches in his geometry lectures. ${ }^{4}$ The key is duality principles defining 1-1 mappings that induce classes of propositions invariant under the mappings. Frege systematically exploits this technique-which in Grundlagen [13] he calls "taking intuitions at other than face value"-in his research in pure geometry. The other approach he describes as involving the possibility 'as a matter of conceptual thought' that one axiom might be false and the others true. He never explains what "as a matter of conceptual thought" means, and the phrase never appears in his writings after 1885 . Frege seems to concede the acceptability of this technique too, though more reservedly. Whatever "conceptual thought" is, independence as Frege understands it [13] involves showing that a set consisting of several axioms plus the negation of another can be used in reasoning without turning up contradictions. Also, in striking contrast to what some interpreters read Frege as saying in the Jourdain sentence, he says directly that the fact that "it is possible to deny any of the axioms" of Euclidean geometry "shows (zeigt) that the axioms of geometry are independent of one another and of the primitive laws of logic . . " ([13], p. 21). ${ }^{5}$

2.2 Sometime after the introduction of the sense-reference distinction, up to the correspondence of 1899-1900 Whatever Frege meant by "conceptual thought", it seems to have occupied a niche that vanishes when Frege works out more carefully what he understands thought and inference to be. At the same time in his teaching and research, Frege was working intensely in the foundations of geometry, with a pronounced tilt to the Plücker-Lie approach. ${ }^{6}$ In correspondence with Hilbert and Liebmann we find the first hints of reservations about independence proofs. Among Frege's complaints is one he will repeat often: Hilbert "illicitly mixes axioms and definitions" by allowing "axioms" to contain meaningless expressions. Frege alludes vaguely to a further "doubt" about Hilbert's independence arguments. Again, Frege understands — and takes Hilbert and Liebmann to understand - the term "independent" thus: axiom $A$ is independent of axioms $A_{1}, \ldots, A_{n}$ if it can be assumed "without contradiction" that $A$ is false while $A_{1}, \ldots, A_{n}$ are true. ${ }^{7}$ An exchange from the correspondence suggests that Frege continues to endorse translation/duality-based approaches. In response to Hilbert's direct question, Frege indicates that he hasn't addressed this issue but he reserves the right to do so ([23], p. 42, 48). (Frege indicates no answer before 1906.)

2.3 1903-1906 Frege repeats his objections to "mixing axioms and definitions" and makes further complaints. The "doubt" of 1900 seems to arise from Hilbert's failure to see that axioms must be true thoughts. Frege rejects approaches that involve taking an axiom to be false. 
Frege also indicates how he thinks independence arguments should be handled. He sketches an approach apparently based on the model of transformations and generalized duality principles. A key is a definition of 'independence' different from the one Frege has acquiesced in until now. Frege pointedly states that these are the proper definitions:

Let $\Omega$ be a group of true thoughts. Let a thought $G$ follow from one or several of the thoughts of this group by means of a logical inference such that apart from the laws of logic, no proposition not belonging to $\Omega$ is used. Let us now form a new group of thoughts by adding the thought $G$ to the group $\Omega$. Call what we have just performed a logical step. Now if through a sequence of such steps, where every step takes the result of the preceding one as its basis, we can reach a group of thoughts that contains the thought $A$, then we call $A$ dependent on the group $\Omega$. If this is not possible, we call $A$ independent of $\Omega$. The latter will always occur when $A$ is false. ([28], p. 334, emphasis added)

To put it roughly and anachronistically for orientation, Frege's new definition is "proof-theoretic" rather than "model-theoretic". It takes as basic the idea of correct inference. But isn't Frege's definition just equivalent to the one that has been used up until now? Isn't a thought $T$ independent of a set $\Omega$ of thoughts in the sense of this definition exactly if $\Omega \cup\{\neg T\}$ is consistent? I think that the answer is, for Frege, no. These two conditions are inequivalent for Frege when $T$ is an axiom, and perhaps generally when $T$ is true. The rest of this paper will fill out the details.

Frege follows this definition with a sketch of what he takes to be the proper approach to proofs of independence. First he lays out a template for relating expressions of the same logical category (names to names, functions to functions of the corresponding arity) holding (as we would now say) logical vocabulary fixed. Constrained permutations of vocabulary induce correspondences among thoughts in the obvious way. Frege then sketches what he calls a new basic law:

Let us now consider whether a thought $G$ is dependent on a group of thoughts $\Omega$. We can give a negative answer to this question if . . . to the thoughts of group $\Omega$ there corresponds a group of true thoughts $\Omega^{\prime}$ while to the thought $G$ there corresponds a false thought $G^{\prime}$. ([28], p. 338)

That is, if the details can be worked out, a thought $G$ will have been proven independent of a group $\Omega$ if there is a family of substitutions of expressions for others, leaving (what we now call) logical constants invariant, transforming the sentences expressing $\Omega$ into sentences expressing a set $\Omega^{\prime}$ of true thoughts, while the sentence expressing $G$ is transformed into a sentence expressing a false thought $G^{\prime}$. Crucially, for Frege, thoughts are evaluated as having the truth-values they actually have. No true thought is treated as false or projected into counterfactual circumstances in which it is false. (Axioms will be paired with other thoughts some of which may be actually false.)

In short, Frege has narrow objections to specific patterns of independence argument but no objections to such arguments tout court. Against this background the Jourdain sentence of 1910 is baffling. The upcoming sections will be structured by the question whether the Jourdain sentence indicates that Frege gave up his sketched theory of independence arguments soon after sketching it. It is, I will argue, an error to take anything of interest to follow about Frege's attitude toward independence arguments as they are restructured in the 1906 sketch. 


\section{The Jourdain Sentence: What Is Frege Saying When He Says "The Unprovability of the Axiom of Parallels Cannot Be Proved?"}

Our first task must be to fill in the context in which the Jourdain sentence appears. The notes-which I will call the "Jourdain notes"-are comments Frege wrote on an English-language article about Frege, written by Jourdain. Jourdain had sent a copy of the manuscript to Frege and then included (translations of) Frege's responses in footnotes. This is, of course, not an ideal source of information. It is unclear how comfortable Frege felt with the English language and he may not have wanted his notes published as they stood. ${ }^{8}$ But in scholarship you play the hand you're dealt. Frege did write the notes and it is up to us to decide what significance to attribute to them.

The sentence occurs in this context. Jourdain cites a passage from Russell and then a series of responses by Frege. This is the final Russell paragraph:

The only ground, in Symbolic Logic, for regarding an axiom as indemonstrable is, in general, that it is undemonstrated. Hence there is always hope for reducing the number. We cannot apply the method by which, for example, the axiom of parallels has been shown to be indemonstrable, of supposing our axiom false; for all our axioms are concerned with the principles of deduction, so that, if any one of them be true, the consequences which might seem to follow from denying it do not follow as a matter of fact. Thus from the hypothesis that a true principle of deduction is false, valid inference is impossible. ([23], p. 182)

Jourdain reports that in reference to 'From the hypothesis that a true principle of deduction is false, valid inference is impossible' Frege writes these two paragraphs (which I will call the "Jourdain passage"):

From false premises nothing at all can be concluded. A mere thought, which is not recognized as true, cannot be a premise for me. Mere hypotheses cannot be used as premises. I can, indeed, investigate what consequences result from the supposition that $A$ is true without having recognized the truth of $A$; but the result will then contain the condition if $A$ is true. But we say thereby that $A$ is not a premise, for true premises do not occur in the concluding judgement. Under circumstances we can, by means of a chain of conclusions, obtain a concluding judgement of the form:

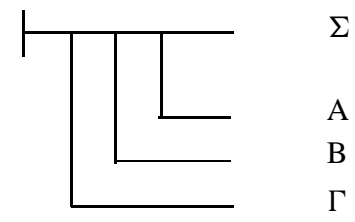

Here $\mathrm{A}, \mathrm{B}$, and $\Gamma$ do not appear as premises of the method of conclusion, but as conditions in the concluding judgement. We can free this judgement from the conditions only by means of the premises $\vdash \mathrm{A}, \vdash \mathrm{B}, \vdash \Gamma$, and these are not hypotheses, since their signs contain the sign of assertion.

The unprovability (unbeweisbarkeit) of the axiom of parallels cannot be proved. If we do this apparently, we use the word 'axiom' in a sense quite 
different from that which is handed down to us. Cf my essays [here Frege refers to the separate essays making up [28]]. ([23], pp. 182-83)

Three points are crucial here. ${ }^{9}$ First, the remark about unprovability is part of a comment on a sentence in which it is suggested that something true could be assumed false. Second the remark comes at the end of a long complaint about the unacceptability of assuming false something known to be true. Third, though Frege refers to the 1906 paper he may be doing so in just one connection: the misuse of "axiom".

In the next few sections, three related observations emerge. First, Frege holds that it is incorrect to suppose a true thought to be false. ${ }^{10}$ Second, Frege explicitly distinguishes two senses of independence: one he uses throughout his writings and the other he introduces for the first time in the 1906 sketch. Third, these two notions of independence are logically equivalent to us, but not to Frege, because of his views on counterfactual suppositions. The Jourdain sentence will turn out to presuppose one of the notions of independence and the 1906 sketch the other, so the Jourdain sentence will not be a rejection of the 1906 sketch.

To bring this point out, I need to build on two separate textual points: (a) Frege's notion of axiom, and (b) Frege's treatment of reductio arguments in the 1914 Logic in Mathematics [18] notes and their relation to the Jourdain remarks.

\section{Frege's Notion of Axiom and His Attitude Toward Counterfactual Assumptions}

In the Jourdain passage as a whole, Frege balks specifically at the strategy of assuming an axiom to be false. Elsewhere he makes his views about demonstrability of axioms clear. "It is part of the concept of an axiom that it can be recognized as true independently of other truths" (Frege [21], p. 168). Frege repeatedly denounces both the suggestion that an axiom could be false and the use of "axiom" to mean anything but what Frege calls the traditional sense. It is worthwhile to cite several examples to convey the obsessive repetition and hyperactive rhetoric. Frege repeats these points with the relentless outrage of a cranky great uncle who ruins every family gathering with his interminable denunciations of Montbatten's perfidy in launching the raid on Dieppe.

A false axiom — where the word 'axiom' is understood in the proper sense-is worthy of exhibition in Kastan's waxworks alongside a square circle. ([28], pp. 334-35)

In Euclidean Geometry certain truths have traditionally been accorded the status of axioms. No thought that is held to be false can be an axiom, for an axiom is a truth. Furthermore, it is part of the concept of an axiom that it can be recognized as true independently of other truths. ([21], p. 168)

From the geometrical source of knowledge flow the axioms of geometry .... Yet even here one has to understand the word 'axiom' in precisely its Euclidean sense. But even here people in recent works have muddied the waters by perverting — so slightly at first as to be scarcely noticeable — the old Euclidean sense, with the result that they have attached a different sense to the sentences in which the axioms have been handed down to us. For this reason I cannot emphasise enough that I only mean axioms in the original Euclidean sense. (Frege [22], p. 273) 


\section{AXIOMS, INDIRECT PROOF, AND INDEPENDENCE ARGUMENTS 277}

Recently a vicious confusion has arisen over the proper meaning of the word 'axiom'. I therefore emphasize that I am using the word in its original meaning. (Frege [20], p. 278)

It must be noted that Hilbert's independence proofs are simply not about real axioms, the axioms in the Euclidean sense, for these, surely, are thoughts. ([28], p. 332)

Mr. Hilbert appears to transfer the independence putatively proved or his pseudo-axioms to axioms proper. . .. This would seem to constitute a considerable fallacy. And all mathematicians who think Mr. Hilbert has proved the independence of the real axioms from one another have surely fallen into the same error. They do not see that in proving this independence, Mr. Hilbert is simply not using the word 'axiom' in the Euclidean sense. ([28], p. 333)

If we use 'axiom' in the Euclidean sense, then contrary to what Mr. Korselt assumes, there cannot be invalid axioms. ([28], p. 328)

One could easily shove many more examples into this cascade. That the honorific 'axiom' was misused was a complaint that Frege evidently thought could never be made often enough. His repeated complaints include the following bits of doctrine, over which Frege was clearly prepared to dig in his heels and fight:

1. Axioms - in the "traditional sense" are true. "False axiom" is incoherent.

2. Axioms - in the traditional sense-are thoughts, rather than sentences or uninterpreted, or incompletely interpreted, strings of symbols. (The latter is what he takes Hilbert to be treating in his Foundations of Geometry [36].)

3. Axioms can be recognized as true independently of other principles. They "neither need nor admit of proof."

Furthermore, there is no doubt that Frege regarded the axiom of parallels as an axiom in this "traditional sense." As late as 1914 we find

Can the axiom of parallels be acknowledged as an axiom in this [the traditional] sense? When a straight line intersects one of two parallel lines, does it always intersect the other? This question, strictly speaking, is one that each person can only answer for himself. I can only say: so long as I understand the words 'straight line', 'parallel', and 'intersect' as I do, I cannot but accept the parallels axiom. If someone else does not accept it, I can only assume that he understands these words differently. Their sense is indissolubly bound up with the axiom of parallels. ([18], p. 247)

A crucial point is involved in the interpretation of these words: "If we use 'axiom' in the Euclidean sense, then contrary to what Mr. Korselt assumes, there cannot be invalid axioms" ([28], p. 328). This may seem like a minor point of terminology. $O f$ course, if axioms are by definition true and evident then nothing can be at the same time false and an axiom. But isn't Frege missing the boat by interpreting Hilbert through a filter that is uncharitable even by Frege's standards? ${ }^{12}$ Say for the sake of argument we grant the point. Hilbert should not use "axiom" for strings with uninterpreted symbols. Principles of good argument tell us to reconstruct Hilbert's views so that the reconstituted view is as strong as possible. Of course, Hilbert is not claiming that something can be at the same time both evidently true and false. His claim is rather that when some thought $T$ is in fact true, and even when it is evident, 
we can intelligibly ask what things would be like if this $T$ were false. But it might seem as if Frege's point - "there cannot be invalid axioms"- only translates into an objection to the silly claim, and not the sensible one.

I think it is a mistake to read Frege that way. He is not just making the trivial point that something cannot be true- - because an axiom in his sense- and at the same time false. He is also making an epistemological point: if a thought is an axiom, one cannot make logical sense of considering the circumstances under which it is false. The objection is not one many people today share, but Frege is not just missing Korselt's point. That is one of the things Frege is getting at with these words, for example:

What does "the proposition obtains" mean? Surely that the proposition expresses a true thought. The latter is either true or false: tertium non datur. Therefore that a real proposition [satz] should obtain under certain circumstances and not under others could only be the case if a proposition [satz] could express one thought under certain circumstances and a different one under other circumstances. This, however, would contravene the demand that signs be unambiguous . . . . Therefore it simply cannot happen that a proposition obtains under certain circumstances but not under others. ([28], p. 329) ${ }^{13}$

In the subsequent discussion, Frege notes a qualification that we have already seen in the Jourdain notes and we will see again: the only room for (what we might today call) a counterfactual assumption is in the antecedent of a (material) conditional:

A proposition that holds only under certain circumstances is not a real proposition. However, we can express the circumstances under which it holds in antecedent propositions and add them as such to the proposition. So supplemented, the proposition will no longer hold under certain circumstances but will hold quite generally. ([28], p. 330)

As those who have scanned the literature on counterfactual conditionals in the 1940s and 1950s will be aware, Frege is on treacherous ground. A standard rhetorical conceit for presenting "the problem of contrary-to-fact conditionals" as a problem was to begin by noting that material conditionals with false antecedents are invariably true.

A few pages later, in the midst of sketching his alternative, Frege repeats the point that thoughts are either true or false, and that therefore counterfactual supposition is illegitimate, and takes it to flow smoothly into his usual complaint:

Mr. Hilbert's axioms, however, are pseudo-propositions which therefore do not express thoughts. This may be seen from the fact that according to Mr. Hilbert an axiom now holds and now does not. A real proposition, however, expresses a thought, and the latter is true or false; Tertium non datur. A false axiom - where the word 'axiom' is understood in the proper senseis worthy of exhibition in Kastan's Waxworks, alongside a square circle. ([28], pp. 334-35)

I am not sure why Frege holds the view he does, though it seems to emerge from his view that logical inference is inference from what is known. ${ }^{14}$ Also, I don't find the view particularly appealing. But the texts indicate it is Frege's view. ${ }^{15}$ It is worth 
noting that this view of false propositions was less distant from the mainstream then. The view of Russell [62] is similar:

There seems to be no true proposition of which there is any sense in saying that it might have been false. One might as well say that redness might have been a taste and not a color. What is true, is true; what is false, is false; and concerning fundamentals there is nothing more to be said. ([62], p. 454) ${ }^{16}$

Russell also cites an article of Moore [49] arguing that the only notion of necessity that makes philosophical sense is generality. ${ }^{17}$ Fair enough: this is what two people who were not Frege thought about modality and counterfactual suppositions. What about Frege? The best direct evidence is cursory and early but here it is:

The apodictic judgement is distinguished from the assertory in that [the apodictic] suggests the existence of general judgements from which the proposition can be inferred, while in the case of the assertory one such an indication is lacking. By saying that a proposition is necessary, I give a hint about the grounds for my judgement.

If a proposition is advanced as possible, either the speaker is suspending judgement by suggesting he knows no laws from which the negation of the proposition would follow or he says that the generalisation of this negation is false. . . "It is possible that the earth will at some time collide with another heavenly body." is an instance of the first kind and "A cold can result in death." of the second. (Frege [15], p. 13)

If Frege held this view of modality as late as 1903/1906, then his remarks about the incoherence of "False axiom" admit of the stronger interpretation that if something is in fact an axiom, it is incoherent to suggest that its negation is possible. If so, then the two definitions of "independence" could fail to be equivalent for Frege because it is impossible (in this epistemic sense) for an axiom to be false. Hence it would be impossible for an axiom to be independent of anything in the first sense of independence, though axioms can be independent of others in the sense defined in the 1906 sketch.

At this point the exegetical questions are delicate, and so I will pause to state what I take to be arguable, and with what degree of confidence, before moving on. My narrow objective is a point for which I think the textual evidence is compelling: For reasons arising from his attitude to false (or necessarily false, or evidently false, . . . ) hypothetical suppositions Frege takes two notions of independence to be inequivalent, and so he treats different philosophical concerns as relevant to each. I think the question of what broader aspects of his philosophical stance prompt his view that the two notions are inequivalent is murkier. I think one of several candidates is better supported than the others, but none seems to me to have overwhelming textual support. In the next section I'll return to the narrow point-first I'll follow out some of the candidate explanations.

Frege's early remarks on modality, though tantalizing, seem to me too meager to bear much weight in an interpretation of anything as late as the Jourdain passage. ${ }^{18}$ Also, it is not easy to square the words about modality with Frege's apparent countenancing of assuming axioms false "as a matter of conceptual thought" in Grundlagen [13]. The issue is complicated and so I will avoid it by building nothing on Frege's view of modality. 
Overwhelming textual evidence can be mustered for the thesis that for Frege, only premises that are true have consequences. ${ }^{20}$ Frege most clearly states his attitude toward (what we would call) inconsistent collections of thoughts in a 1917 letter to Dingler. Frege is discussing Dingler's "proposition II/4" which reads "if we succeed in inferring logically from a group of premises that a certain statement both holds and does not hold for one of the concepts contained in the premises, then I say This group of premises is contradictory, or contains a contradiction." ${ }^{21}$ Frege comments:

Is this case at all possible? If we derive a proposition from true propositions according to an unexceptionable inference procedure, then the proposition is true. Now since at most one of two mutually contradictory propositions can be true, it is impossible to infer mutually contradictory propositions from a group of true propositions in a logically unexceptionable way. On the other hand, we can only infer something from true propositions. Thus if a group of propositions contains a proposition whose truth is not yet known, or which is certainly false, then this proposition cannot be used for making inferences. If we want to draw conclusions from the propositions of a group, we must first exclude all propositions whose truth is doubtful. The schema of an inference from one premise is this:

' $A$ is true, consequently $B$ is true.'

The schema of an inference from two premises is this:

' $A$ is true, $B$ is true consequently $\Gamma$ is true.'

It is necessary to recognize the truth of the premises. When we infer, we recognize a truth on the basis of other previously recognized truths according to a logical law. Suppose we have arbitrarily formed the propositions ' $2>1$ ' and 'If something is smaller than 1, then it is greater than 2' without knowing whether these propositions are true. We could then derive ' $2>2$ ' from them in a purely formal way; but this would not be an inference because the truth of the premises is lacking. And the truth of the conclusion is no better grounded by means of this pseudo-inference than without it. And this procedure would be useless for the recognition of any truths. So I do not believe your case II/4 could occur at all. ([23], p. 16-17, emphasis added)

Frege does not even accept reasoning from sets of premises that contain the negation of an axiom. This hard line is also adopted in a draft letter to Jourdain (ca. January 1914):

If a proposition asserted with assertoric force expresses a false thought, then it is logically useless and cannot strictly speaking be understood. A proposition uttered without assertoric force can be logically useful even though it expresses a false thought, for example, as part (antecedent) of another proposition. What is to serve as the premise of an inference must be true. Accordingly, in presenting an inference, one must utter the premises with assertoric force, as the truth of the premises is essential to the correctness of the inference. $([23], \text { p. 79 })^{22}$

Frege's discussion of reductio arguments in [18] helps bring out his view that it is a mistake to even hypothetically consider inferences from thoughts that are not true.

The axioms of a system serve as premises for the inferences by means of which the system is built up . . . since they are intended as premises, they have to be true. An axiom that is not true is a contradiction in terms. ([18], p. 244) 
Frege then moves to consider hypothetical reasoning. The first few lines repeat yet again Frege's boilerplate—axioms are true, premises are true-but even at the cost of a few extra lines I thought it best to quote the passage at full length. This will help convey the sheer relentlessness with which Frege hammers at this point over and again. $^{2}$

Let us assume that we have a sentence of the form 'If $A$ holds, so does $B$ '. If we add to this the further sentence ' $A$ holds' then from both premises we can infer ' $B$ holds'. But for the conclusion to be possible, both premises have to be true. And this is why the axioms have to be true, if they are to serve as premises. For we can draw no conclusion from something false. But it might perhaps be asked, can we not, all the same, draw consequences from a sentence which may be false, in order to see what we should get if it were true? Yes, in a certain sense this is possible. From the premises

If $\Gamma$ holds, so does $\Delta$

If $\Delta$ holds, so does $E$

We can infer:

If $\Gamma$ holds, so does $E$

From this and the further premise

If $E$ holds, so does $Z$

We can infer

If $\Gamma$ holds, so does $Z$

And so we can go on drawing consequences without knowing whether $\Gamma$ is true or false. But we must notice the difference. In the earlier example the premise ' $A$ holds' dropped out of the example altogether. In this example the condition 'If $\Gamma$ holds' is retained throughout. We can only detach it when we see that it is fulfilled. In the present case, ' $\Gamma$ holds' cannot be regarded as a premise at all. What we have as a premise is:

If $\Gamma$ holds, so does $\Delta$

And thus something of which ' $\Gamma$ holds' is only a part $\ldots$. so strictly speaking we cannot say that consequences are here being drawn from a thought that is false or doubtful. ([18], p. 244-45)

Next Frege considers indirect proofs and repeats that when it looks like one is making a false assumption for purposes of reductio, the argument can be restructured so that "At no point in the proof have we entertained [the reductio assumption] even as a hypothesis" ([18], p. 246, emphasis added).

At exactly this point in the "Logic in Mathematics" notes, Frege moves to this next topic, in a seamless way that suggests he sees it as contiguous with what went before:

In an investigation of the foundations of geometry it may also look as if consequences are being drawn from something false or at least doubtful. Can we not put to ourselves the question: How would it be if the axiom of parallels didn't hold? ([18], p. 247, Frege's emphasis)

Aha! Now that is what we are looking for! Surely this will clear things up. And in fact I think the subsequent discussion does turn out to be a decisive clue. But I will have to put off the examination for one section; I need to first revisit the Jourdain remarks to lay a few more foundation stones before pressing further into [18]. 


\section{The Jourdain Remarks Again-Reductio ad Absurdum Arguments}

Revisiting the Jourdain remarks with this narrow focus, one point leaps out. They are almost completely devoted to the points we have just seen. Only true thoughts can be premises of inferences. Any argument that involves putting a true thought forward as false, even "hypothetically" is unacceptable. Reductio ad absurdum arguments, to be acceptable, have to be given as proofs of conditionals.

Say that we just say, "Yes, Mr. Frege, you are right. Sentences must express thoughts." We can treat Hilbert's "axioms" the way Pasch [50]-to consider the most obvious cognate- treats his axioms. They are contentful sentences which can be reinterpreted or considered in circumstances where they fail. As it happens, this is just what Korselt does in his essays (Korselt [42], [43]). Doesn't this answer Frege's objections? No: a further issue remains even if we apply this patch. To prove an axiom independent in what Frege seems to regard as the accepted sense of "independent" we have to make sense of the possibility that all but one of the axioms plus the negation of the remaining one are true, which he has no room for. (It is crucial that this is different from the sense of independence that he defines later, in 1906.) This objection to independence arguments - as Hilbert, Liebmann, Korselt, and so on, understand "independence"- applies even if axioms are thoughts rather than partially interpreted symbol strings.

Frege's stance looks less odd in its historical setting. In an illuminating discussion of indirect proof in the nineteenth century, Mancosu cites critical studies by Bolzano, Lotze, Trendelenburg, and Wundt, with each of whom Frege can be established to be at least passingly familiar. ${ }^{24}$ Frege was also apparently familiar with Sigwart's Logic which critically examines indirect proof. ${ }^{25}$ There was also criticism from the mathematical side. The later intuitionist critique is best known today, though misgivings appeared earlier and extended more widely. ${ }^{26}$ As Mancosu recognizes, there is an especially close and intriguing parallel with Bolzano since Bolzano shared Frege's picture of inference as proceeding from truths to truths. ${ }^{27}$ These parallels are enough to make the point: though they would be oddities today, both the view of inference as proceeding from truths to truths and skepticism toward reductio arguments were then in the air. ${ }^{2}$

Frege's view is more intelligible if we bear in mind that he takes logical relations to be relations among thoughts. Recall the well-known interpretation of "plane" as "surface of a sphere" and "line" as "great circle of a sphere". On this interpretation, the axiom of parallels comes out false, if by "axiom of parallels" we mean the sentence. But Frege means the thought the axiom (actually) expresses. With the alternate interpretation, the sentence expresses a different thought. So, Frege might put the question: What reason do we have to judge the logical properties of one group of thoughts - the Euclidean axioms - on the basis of the truth-status of these other thoughts about great circles on spheres?

This is not a rhetorical question. It is a real question which has at least one straightforward answer, which is the one Frege gives in 1906. In short, we know these thoughts are logically relevant to one another because the second set arises from constrained permutations of the objects and functions referred to by (what we would now call) the nonlogical vocabulary in the sentences expressing the first set. There is absolutely no need to consider reinterpretation, but only 1-1 correspondences, in making this point. 
At no point do we have to say that a true sentence is false or could be false or is hypothetically posited as false. Frege takes pains to ensure that the mappings given by the duality principles correlate expressions in a sequence of sentences expressing true thoughts with another sequence of thoughts. This does not mean that any true sentence is assumed false, but rather a true sentence is shown to admit of a dualitystyle correlation with a different sentence, possibly expressing a thought that is false. No assumptions contrary to fact are made. No axioms are taken to be false. Why then the complaints in the Jourdain passage about assuming "axioms" false, and misunderstanding the notion of "axiom" and so on? What does that have to do with independence arguments as sketched in [28]? I think the answer to this rhetorical question is: nothing. The remarks only apply to arguments for independence as Frege takes that notion to be generally understood, not as he redefines it in 1906. All the objections Frege raises to independence arguments after 1906 apply only to independence as construed in the pre-1906 way.

Prior to 1906, Frege takes"independence" to involve assuming an axiom to be false. Frege himself defines "independence" this way in the correspondence of 1899-1900, and this definition also informs the discussion of independence in the Grundlagen [13] sixteen years earlier. When Frege turns, in 1906, to sketch how he has come to think "independence" should properly be defined to carry out independence arguments among thoughts, he defines it differently: a thought $T$ is independent of others $\Omega$ if there is no sequence of logical steps leading from $\Omega$ to $T$. The first and only time that this definition appears in Frege's writings is in the 1906 sketch, as he is spelling out how he feels that the whole topic ought to be restructured. We are, of course, today inclined to regard these definitions as equivalent, but that is because we lack Frege's reluctance to place a turnstile in front of a sentence expressing the negation of an axiom.

\section{The Jourdain Passage in Light of Frege's Discussion of Reductio Arguments: The Two Notions of Independence Post-1906}

Two key features of the interpretation of the Jourdain remark that I am proposing are these:

1. The reference to the [28] article is meant to support the narrow point about Hilbert's (mis)use of the word "axiom";

2. The remark stating the unprovability of the "unprovability of the parallels axiom" is meant narrowly, to reject arguments that require an axiom to be assumed false, not arguments purporting to show that a thought doesn't follow from others.

The most striking support for this reading is a passage of the 1914 lecture notes [18]. The relevant part of the notes so closely duplicates the Jourdain passage as to appear to be a rewriting of it. It will be useful to first quote the whole passage, broken up by a running commentary. The paragraph opens with a distinction of two ways of understanding independence questions:

In an investigation of the foundations of geometry, it may also look as if consequences are being drawn from something false or at least doubtful. Can we not put to ourselves the question: How would it be if the axiom of parallels didn't hold? Now there are two possibilities here: either no use is made at all of the axiom of parallels, but we are simply asking how far we can get with 
the other axioms, or we are straightforwardly supposing something which contradicts the axiom of parallels. It can only be a question of the latter case here. But it must constantly be borne in mind that what is false cannot be an axiom, at least not if the word 'axiom' is being used in its traditional sense. What are we to say then? Can the axiom of parallels be acknowledged as an axiom in this sense? When a straight line intersects one of two parallel lines, does it always intersect the other? This question, strictly speaking, is one that each person can only answer for himself. I can only say: so long as I understand the words 'straight line', 'parallel', and 'intersect' as I do, I cannot but accept the parallels axiom. If someone else does not accept it, I can only assume that he understands these words differently. Their sense is indissolubly bound up with the axiom of parallels. ([18], p. 247, emphasis added)

At the outset Frege distinguishes the question of what can be proven from a fixed set of axioms from another question of whether or not it is acceptable to assume the axiom of parallels false. He only quarrels with the second. Only the first is at issue in the discussion of the "new basic law" in [28]. As the passage continues, Frege writes that the axiom of parallels is an axiom in his sense. The subsequent discussion, aimed solely at the second possibility, is a nearly verbatim repetition of the Jourdain passage:

Hence a thought which contradicts the axiom of parallels cannot be taken as the premise of an inference. But a true hypothetical thought, whose condition contradicted the axiom, could be used as a premise. This condition would then be retained in all judgements arrived at by means of our chains of inference. If at some point we arrived at a hypothetical judgement whose consequence contradicted known axioms, then we could conclude that the condition contradicting the axiom of parallels was false, and we should thereby have proved the axiom of parallels with the help of the other axioms. But because it had been proved, it would thereby lose its status as an axiom. In such a case we should really have given an indirect proof.

If, however, we went on drawing inference after inference and still did not come up against a contradiction anywhere, we should certainly become more and more inclined to regard the axiom as incapable of proof. Nevertheless, we should still, strictly speaking, not have proved this to be so. ${ }^{29}$

Now in his Grundlagen der Geometrie Hilbert is preoccupied with such questions as the consistency and independence of axioms. But here the sense of the word 'axiom' has shifted. For if an axiom must of necessity be true, it is impossible for axioms to be inconsistent with one another. But obvious as it is, it seems not to have entered Hilbert's mind that he is not speaking of axioms in Euclid's sense when he discusses their consistency and independence. ([18], p. 247)

Here the points made in the Jourdain passage are made in the order they are made in that passage. ${ }^{30}$ (Some additional points are also put forward.) He complains about Hilbert's misuse of 'axiom' and repeats his assertion that Hilbert's purported independence results are thereby vitiated. The discussion is explicitly restricted to independence results that involve assuming an axiom to be false. The type sketched in [28] has been set aside as a separate issue, which Frege does not discuss. (Though 
he hints that the axiom of parallels is not, in fact, provable from the other Euclidean axioms and that the record of failure could give reason to believe this.)

\section{What the Jourdain Sentence Means-Really}

We are now in a position to summarize and review the case. When Frege says "the undecidability of the axiom of parallels cannot be proved" he means to reject only independence arguments as he interprets the word "independence" prior to 1906. The objections Frege raises to Hilbert's style of independence argument turn on features of those arguments which would not be shared by independence arguments as reconstructed in 1906. In particular, Frege constantly repeats the complaint that the problem with Hilbert's arguments lies in a misuse of "axiom", and in the Jourdain notes this is the sole point concerning which Frege refers us to the essay [28]. Yet this is a problem only for the arguments which define independence of $A$ from $T$ as the unprovability of a contradiction from $T \cup\{\sim A\}$, or the possible truth of $T \cup\{\sim A\}$. The only reason for rejecting independence arguments Frege gives later, in the 1914 notes, explicitly assimilates the issue to the rejection of taking axioms to be false, and explicitly exempts the 1906 notion of independence. It seems reasonable to take the thrust of the Jourdain remarks, composed within a few years of [18], and which seem to be repeated nearly verbatim in [18], to be aimed at the same target.

For Frege, the definition he provides in 1906 of "independence" is not equivalent to the one he used before, which he takes to be the generally accepted one. For Frege, an axiom might not be provable from other given axioms, but it is nonetheless incoherent to posit its negation, even "hypothetically." Thus there are two identifiable trains of thought in Frege about independence that show themselves as early as Grundlagen [13] and persist through 1914. One attitude-as an abstract matter of "conceptual thought" - he seems to hold at arm's length from the outset and finally abandons. The other-a Plücker style approach with affinities to duality and transfer principles-he embraces both in his mathematical work and his philosophical discussions from Grundlagen onward without change. On this account, Frege's twists and turns are intelligible. ${ }^{31}$ There is considerable textual support for the one eccentric view we end up crediting him with. Frege repeatedly states the crucial points that false sentences have no consequences and that hypothetical assumptions are only acceptable as antecedents of material conditionals.

I am fully confident that this reading of the sentence is correct but as indicated there is room for reservations. In particular, I am troubled because in the Jourdain sentence Frege writes "unprovability" rather than "independence". I explain this by noting that he is commenting on a passage in which Russell uses "indemonstrability" in the way Frege takes most people to use "independence", and Frege is choosing the terms that fit the context. But this does leave a nagging doubt. ... ${ }^{32}$

\section{Why It Matters What the Jourdain Sentence Isn't Saying-The "No Metatheory" Interpretation}

A dialectical risk arises with any specific interpretation of the Jourdain sentence, because of the sentence's potential conflict with the 1906 sketch of a transformationbased approach to independence proofs. I don't want to leave the impression that if the interpretation given above is wrong it is likely that the Jourdain sentence is a rejection of the 1906 sketch. It isn't. The Jourdain sentence is a puzzling, isolated remark and 
it is prudent to allow for the possibility that some revision might be necessary in the positive story told here. But it is a long jump from there to the thesis that Frege had abandoned the "new science" he sketched in [28]. I have no doubts whatever about the negative point that whatever the Jourdain notes may be saying, they are not saying that.

The 1906 sketch gestures at a general duality-based method for proving the independence of a given thought from a collection of other thoughts. The Jourdain sentence says that there is no proof of the indemonstrability of the axiom of parallels. Why should we take the latter to be relevant to the former? There are at least three live possibilities of interference: (a) Perhaps Frege really does mean unprovability, not independence. (b) Perhaps Frege rejects the test for axioms, not thoughts generally. (c) Perhaps Frege rejects the application of the independence test to the axiom of parallels for reasons specific to the axiom of parallels, not axioms generally. Each of these has something to be said for it, and each is, I think, more likely than that the Jourdain sentence rejects the 1906 sketch.

The negative point is worth pressing for two reasons. First, the interpretation of the Jourdain sentence plays a key role in a current scholarly controversy over Frege's attitude toward metatheory. Second, the negative point, like the Fermat Theorem, is less intrinsically interesting than it is a fruitful target. A range of independently interesting and illuminating historical detail has to be mustered to provide the background against which the negative point becomes evident.

Ricketts, in [58], has drawn exactly the conclusion that the Jourdain sentence conflicts with the 1906 sketch. $^{3}$

I have argued that Frege does not embrace his "new science": that he remains skeptical of it. Indeed, in 1910, commenting on Russell's claim that the principles of deduction cannot be shown independent by the method used in the case of the independence of the parallel postulate, Frege flatly asserts, "The unprovability of the parallel axiom cannot be proved." and cites his 1906 paper on Hilbert. ([58], p. 185)

This terse statement belies the importance of the sentence to his overall interpretation. Ricketts is one of the most prominent exponents of a view that has become a fixture in recent North American Frege scholarship: the view that Frege was committed to rejecting what Ricketts calls "metatheory". ${ }^{34}$ There is some unclarity in Ricketts's writings as to just what "metatheory" is, but for our purposes it will suffice to take the view to be that Frege was committed to regarding soundness arguments for modus ponens, and model-theoretic consistency and independence proofs as in some way unintelligible. ${ }^{35}$ What of the many places where Frege does what he is claimed to be committed not to do? Ricketts tries to explain most of these away as occupying a special category Frege calls "elucidation". I find these explainings away extremely forced and unconvincing, but for the sake of the argument of this paper I will leave them uncontested. This paper will pick up on a point that even Ricketts grants: the discussions of soundness and independence in the 1906 [28] sketch cannot plausibly be explained away as "elucidation". Ricketts confronts this direct counterevidence by arguing that Frege "has reservations" about the proof method he sketches and that he rejects it openly a few years later. Ricketts then attempts to explain the attributed reservations and retraction by appealing to Frege's supposed anti-metatheoretic stance. This deftly essays a scholarly pirouette, transforming a flat refutation into 
support: "appearances notwithstanding. . . Frege's foray into metalogic confirms the van Heijenoort-Dreben [no metatheory] interpretation" ([58], p. 170). ${ }^{36}$ The Jourdain sentence is the only direct textual evidence supporting this bold reading of [28]. This reading of [28] is in turn indispensible for the speculative "no metatheory" interpretation. For the Ricketts view, a lot rests on this one sentence.

I say that the Jourdain sentence is the only textual evidence that can be plausibly argued to directly support the Ricketts interpretation because the words of the [28] sketch themselves skate a thin line. Frege expresses no doubts, but he writes as one would expect someone as careful as Frege to write about a sketch. He nods at the details to be worked out and says that working them out may not be easy. But he doesn't indicate any objections of principle. I am inclined to think that if Frege thought that there were reasons why this approach couldn't work in principle he would have mentioned them or at least alluded to them. So the absence of objections suggests his worries were "narrowly technical": can the many remaining details be worked out successfully? Ricketts apparently feels that if Frege wasn't dubious of the possibility that the details could be worked out he would have said explicitly that he wasn't, so the fact that Frege doesn't explicitly repudiate all doubts is, for Ricketts, significant. The silence is taken to indicate "skepticism".

Of course, to make out the relevance of the Jourdain sentence to the 1906 sketch requires some filling in of detail—which Ricketts does not give. That sketch outlined a general technique for proving the independence of one thought from a group of others. The remark denies that one can prove the indemonstrability of one specific thought. Is it obvious that the specific claim is anything more than a particular, isolated exception to the general one? Ricketts appears to think so, and one can, with some assurance reconstruct why. The assumption seems to be that, although Frege spoke of thoughts in general in the [28] sketch, the only real issue would have been the parallels postulate. But in fact there were many independence questions that Frege would have been engaged with in his ongoing research. Several of them were addressed in Hilbert [35]. Most of them were different from the axiom of parallels in relevant ways. Several were integral to Frege's teaching and research in the 1890s; two of them were at the heart of Grundgesetze II, published in $1903 .{ }^{38}$

\subsection{Possibility I-Frege Means "Unprovability" When He Says "Unprov-} ability" As I indicated, what reservations I have about my interpretation of the Jourdain sentence arise from Frege's use of "unprovability" rather than "independence". Even allowing for unclarity about the circumstances in which the Jourdain notes were edited into a finished form for publication, and even though Frege is commenting on a passage in which Russell talks of "indemonstrability," it still doesn't seem unreasonable to think that Frege tended to use language more precisely than that. However, this still doesn't indicate that the Jourdain sentence rejects the 1906 sketch. The precise language of the Jourdain sentence doesn't conflict with the 1906 sketch. [28] sketches a technique for showing that certain thoughts cannot be proven from some other given set of thoughts. Frege does not say that it is impossible to demonstrate the axiom of parallels from the remaining Euclidean axioms. He denies that it is possible to show the indemonstrability (Unbeweisbarkeit) of the axiom. $\mathrm{He}$ is commenting on some lines where Russell speaks of demonstrability and indemonstrability without qualification. This is the sort of misleading statement Frege is elsewhere quick to jump on. ${ }^{39}$ Frege's point might just be: 
1. The axiom of parallels is self-evidently true (as we have seen he believes this even as late as 1914).

2. It is therefore ipso facto demonstrable either because it serves as its own demonstration or because there will always be infinitely many other selfevident variations, differing in sense, from which it can be deduced.

But the issues here are complicated and so I will leave the discussion to an endnote. ${ }^{4}$ The point is that insistence on a precise reading of Frege's words does put a roadblock in the way of my positive reading, but not in a way that leads to a clash with the 1906 sketch.

8.2 Possibility II-Frege Rejects the 1906 Test Only for Axioms The 1906 sketch attacks the question of the dependence and independence of axioms by immediately switching the topic to the more general case of the dependence relations among thoughts. All of the subsequent reflections pertaining to the outlined "new science" including the sketch of the "new basic law" are in these terms.

This is one point where details of Frege's mathematical environment can make a difference to the interpretation of his philosophical work. If one assumes (as Ricketts appears to) that the sole geometrical independence question of interest to Hilbert, Frege, and their readers is that of the axiom of parallels, and that the Hilbert argument concerning the axiom of parallels caught Frege off guard, then it could seem plausible that such a sentence clipped out of an incidental passage could be a flat rejection of the sketched "new science" of [28]. ${ }^{41}$ The fact that many independence problems are considered by Hilbert, and several of them pertain to theorems on which Frege devoted serious research effort, in both his foundational and his nonfoundational research, makes the automatic move from Frege's statement about a specific independence claim to a wholesale rejection of a general technique far less credible.

Here is a digest of some details that are presented in Tappenden [69]. Though [35] addresses many independence questions, the axiom of parallels is not treated as a major target. ${ }^{42}$ For a turn-of-the-century geometer, it was old news. Hilbert's eye-opening discoveries concerned the deductive relations among central theorems of projective geometry and algebraic conditions on coordinates. It is crucial to recognize how incidental to Hilbert's Grundlagen the independence of the axiom of parallels is, and how casually Hilbert tosses the argument off. Here is the whole argument with not a syllable omitted:

[The axiom of parallels] is independent of all the other axioms. This may be most easily shown in the following well-known manner. As the individual elements of a geometry of space, select the points, straight lines, and planes of the ordinary geometry . . . and regard these elements as restricted in extent to the interior of a fixed sphere. Then, define the congruences of this geometry by aid of such linear transformations of the ordinary geometry as transform the fixed sphere into itself. By suitable conventions, we can make this "non-Euclidean geometry" obey all of the axioms of our system except the axiom of Euclid. Since the possibility of the ordinary geometry has already been established, that of the non-Euclidean geometry is now an immediate consequence of the above considerations. ([35], p. 22, emphasis added) ${ }^{43}$ 
This is, of course, not so much a proof as a nod in the direction of a proof that has been well known for almost thirty years. Hilbert treats it as going without saying that the formulation of this argument in the framework he has developed will be routine.

In 1899 Frege told Hilbert that he had been working on the foundations of geometry in recent years "though without publishing anything," and the documentary record bears out that he was up to his ears in ongoing geometric research. Frege led seminars and lectured on geometry throughout the 1880s and 1890s. He discussed it with Gutzmer and apparently several times weekly with Thomae. The record of his Nachlass shows notes and drafts indicating serious engagement with problems of pure geometry. Here is a digest of some details of Tappenden [70] that are relevant to assessing the Jourdain sentence. The subject is too rich to do more than pick out one strand here. I will concentrate on one point to which Frege's nonfoundational research can be tied especially closely: the relationship among Desargues theorem, Pappus's theorem, and the so-called Fundamental Theorem of Projective Geometry. ${ }^{44}$ As we now know, given a core set of incidence axioms for projective geometry in the plane, Pappus's theorem is equivalent to the Fundamental Theorem. Desargues theorem follows from the Pappus theorem but not conversely. Much of this was presented already in the early versions of Hilbert's Foundations that Frege commented on.

The Fundamental Theorem states that a projective mapping between two lines is completely determined if one is given three corresponding pairs of distinct points on the lines. ${ }^{45}$ This is employed in a crucial way in the development of a metric given projective geometry plus fixed points, as worked out by Cayley and Klein in the 1870s. That Pappus and Desargues are used in the proof of the Fundamental Theorem was noted already in 1890 in an article (Weiner [80]) that Frege is likely to have seen. ${ }^{46}$ Schur [65] proved, in the high-profile Mathematische Annalen, that these theorems are necessary for the proof of the Fundamental Theorem. ${ }^{47}$

Projective geometry was then a major research area, and it was at the heart of Frege's geometric work. ${ }^{48}$ All of Hilbert's early geometric exploration was formulated in an explicitly projective context (see Toepell [78]).

This is as one would expect, given the attitude that prevailed toward projective geometry as a "geometry in general." Cayley was voicing a widespread opinion when he made his renowned pronouncement: "Euclidean geometry is a part of descriptive geometry and descriptive geometry is all geometry." ${ }^{49}$ Frege would have been taken to be displaying a similar attitude in his remarks about 'general projective geometry' in Frege [29], p. 95.

One last principle that should be mentioned is the "axiom of Archimedes". ${ }^{50}$ As with the parallels axiom, the issue of dependence and independence relations involving this axiom had been alive for decades. Klein in the second of his papers on non-Euclidean geometry [40] noted that the von Staudt procedure for assigning coordinates to points in a projective plane lacked rigor because von Staudt had not made the dependence on this axiom explicit. Following Klein's advertisement of the point, it had become commonplace. The questions of what did and did not follow from this axiom were extensively investigated between 1890 and 1905. Again, this was an observation that was put forward and accepted as a part of straightforward mathematical practice rather than a point that related only to foundational, or epistemological issues. If Frege had any objections to this sort of investigation, his attitude to ordinary mathematical practice would have been highly revisionary. Frege is likely to have been familiar with at least some of this work, since he uses the relatively new 
expression "axiom of Archimedes" and proves the Archimedean axiom for positive classes as one of the culminating results of Grundegesetze II.

To appreciate the impact of the Hilbert foundations of geometry lectures and the subsequent editions of [35] it is essential to be aware that they were, and were regarded as, the capstone of this sequence of events. (Indeed, Schur openly and quite justly complained that Hilbert had failed to adequately credit him, and Weiner ought to have complained too (see [78]). [35] developed an axiomatization of projective geometry in terms of a basic set of axioms governing the incidence of points and lines, with the Pappus and Desargues theorems as further axioms (in Hilbert's sense of "axiom" of course, not Frege's). Hilbert showed that relative to his incidence axioms, (in the plane) Pappus is independent of the Desargues theorem, but not conversely, so the Fundamental Theorem is also independent of the Desargues theorem. (Hence the Desargues theorem alone will not support the introduction of a metric given three fixed points.) Furthermore, Hilbert's arguments and analysis were largely new: though these particular facts about dependence and independence results had been suspected and speculated about for nearly ten years, for many of them Hilbert provided the first argument that could be taken to be a proof.

Would these results have been of any interest to Frege? Unquestionably. This point is crucial, and so perhaps it deserves italics: the theorems just described-Pappus, Desargues, the Fundamental Theorem of projective geometry, and their deductive relations were far more central to Frege's ongoing mathematical work than the parallels axiom. In fact, both Desargues's theorem (which Frege calls "the theorem on perspective triangles") and the Fundamental Theorem were addressed in lectures Frege gave to the Jena Mathematical Society. ${ }^{5}$

These questions would also have been on the minds of those with whom Frege discussed geometry. The 1894 textbook issuing from Thomae's Jena lectures on the pure projective treatment of conics discusses these matters and reflects on what principles might be needed to prove which others (cf. Thomae [77], esp. 24-25). Frege also indicates, in a 1902 letter to Huntington, an antecedent familiarity with some Huntington papers in which related topics, including the role of the axiom of Archimedes, are discussed (cf. [23], pp. 57-59). It seems likely that Frege thought the axiom was an axiom in his sense, since he calls it "Archimedes axiom". It is possible, of course, that he was just following current usage, but as we've seen he tended to be fastidious about his use of the "A-word". (Though note that it also indicates a certain softness in Frege's view that axioms "neither need nor admit of proof" that he proves something he calls an axiom in Grundgesetze II.)

Now, of course, Frege's main research objective in the years before 1903 was Grundgesetze II. Here too we find Frege engaged in sustained work that engages with these dependence and independence problems relating geometric formulas. Indeed, the book culminates in two theorems among those that have just been mentioned. First, Frege undertakes the proof of the Archimedes axiom for his reconstruction of the real numbers. In addition, the major task of the final part of Grundgesetze II was a proof that the multiplication relation Frege had defined is commutative. ${ }^{52}$ Given the connection Hilbert had unearthed, this meant Frege was proving the Pappus theorem (and therefore the equivalent Fundamental Theorem, the projective invariance of the cross-ratio, and so on), if his "positivklassen" were used as plane coordinates. Ascertaining just how diligently Frege looked into this can only be a matter for speculation 
barring new archival discoveries. But it is inconceivable that a working mathematician with Frege's background, working on the final theorem of Grundgesetze II would have failed to rummage for insight in the link Hilbert unearthed between commutativity in quantitative domains and the Pappus theorem in the geometries coordinatized by those domains.

As already noted, in [28] Frege attacks the question of the dependence and independence of axioms by immediately moving the topic to the more general case of dependence relations among thoughts. All of the subsequent reflections pertaining to the outlined "new science" including the sketch of the "new basic law" are in these terms. The "new basic law" could well be applicable to, say, the relation between Desargues's theorem and the Fundamental Theorem. As such, it would go to the heart of several mathematical questions that were then the subject of intense scrutiny in Frege's professional mathematical environment. Do we have any reason to think that Frege thought that this independence result couldn't be demonstrated by using a rigorously fleshed out version of his "new basic law"? The only textual evidence is the Jourdain passage and even that requires some extrapolation from what Frege says; these are not axioms in Frege's sense, nor are they principles specific to Euclidean geometry.

These details of Frege's background help nail down the specific point that Frege would have regarded issues of the dependence and independence of thoughts as posing live geometrical questions. [28] sketches a general technique for demonstrating the independence of one thought from another. Though Frege used the axiom of parallels as a handy example, he would not have expected his audience to think of the axiom of parallels as the only independence question of interest. Rather, he would have expected his audience to think of his sketch as relevant to these broader ongoing investigations. The Jourdain sentence only gives even the initial appearance of a rejection of the 1906 sketch if we read it against the background of an erroneous picture of the state of thinking about independence arguments in 1899-1910.

\subsection{Possibility III-The Jourdain Sentence Rejects the 1906 Test Only for the} Axiom of Parallels The point just discussed - a brace of independence questions occupied the attention of serious geometers in the 1890s-makes salient another possibility. The Jourdain sentence may indicate some suspicion just about the claimed independence of the parallels axiom from the other Euclidean axioms. This possibility is particularly interesting in that it entwines with a large question mark in the history of mathematics in the period.

In letters to Liebmann and Hilbert, Frege emphasizes that his animadversions have solely to do with Euclidean geometry. ${ }^{54}$ Contemporary readers take the stress to indicate a contrast with Hilbert (that is to say, "the axioms of Euclidean geometry" as opposed to "those things Hilbert calls axioms of that thing Hilbert calls geometry.") Like everyone else, I take Frege to intend that contrast, based on how this interpretation fits with the other things Frege says. But (apparently unlike everyone else) I don't think that this is a sure thing. It is possible and not unlikely that with this emphasis Frege intended, and would have expected Liebmann to infer, a contrastive stress between "Euclidean geometry" and "other systems of axioms, for example, projective geometry". On this reading-which I think is wrong, but not obviously so-Frege's complaints in the Jourdain notes concern just the axiom of parallels. 
The message of this section requires more space than I can give it here, but I hope a few sketchy paragraphs will not be amiss. ${ }^{55}$ In geometry and bordering areas, the period from 1870-1910 was exceedingly complicated. One of the reasons is that many of the proofs offered were fallacious or in one way or another confused. Irrespective of any philosophical or logical scruples Frege may have had, he would have had much to object to in the work around him on mathematical grounds alone.

This stands in opposition to a picture that seems to inform the interpretation of Frege's foundations. The picture, in caricature form, is this: the mathematicians of the late nineteenth century kept producing clear and well-defined "mathematical results" supported by proofs which were not formal, but nonetheless watertight examples of "informal rigor". Then, according to the picture, the philosophers and philosophically-minded mathematicians scrambled to find the proper philosophical interpretation of these results and produce logical duplicates: thus we had the work of Frege, Russell, and so on. ${ }^{56}$ This caricature is so crude that perhaps no one would accept it exactly as it stands. But it is close enough to attitudes that are occasionally encountered that a warning can be seen to have some point: it should not be assumed that the mathematical work Frege was discussing was mathematically above reproach. Some writers made more mistakes and some made fewer, but-as the universal language of bureaucrats has it- "mistakes were made." Nor should it be assumed that Frege's foundational proposals were unrelated to the mathematical lacunae. Now that Hilbert is lodged snugly in the pantheon, we tend to forget that Frege had no shortage of narrowly mathematical reasons to be dissatisfied with Hilbert's early foundations. ${ }^{5}$ The mathematical details are complicated, and the history has not been completely sorted out. ${ }^{5}$

Hilbert was far less error-prone than, say, Klein but even he slipped: for example, the first edition of Foundations of Geometry doesn't properly formulate the needed continuity axioms, and all editions, even the most recent, fail to give an adequate argument for the crucial fact that the Pappus theorem implies the Desargues theorem. ${ }^{59}$ Given what Frege was working on at the time-including the axiom of Archimedes, a major theorem of Grundgesetze II-Frege would probably have noticed the problem with continuity. Given the connection between commutativity of operations and the Pappus theorem, he might have noticed the looseness in the other proof too.

\section{Recap: Why It Is Unlikely That the Jourdain Sentence Indicates a Rejection of the 1906 Sketch}

Here is how much we would have to accept to regard the Jourdain sentence as a rejection of the 1906 sketch:

1. We would have to accept that Frege meant "independence of the other Euclidean axioms" when he wrote "unprovability" (I do think this is likely, for reasons indicated above, though it indicates loose usage on Frege's part.)

2. Even given (1), we would have to accept that Frege's comment in the Jourdain passage was motivated by a general worry rather than one specific to the axiom of parallels.

3. Even if we were to accept (1) and (2) we would need to accept that Frege's basis for rejecting the claim that the axiom of parallels could not be shown unproveable from the other Euclidean axioms arose from concerns pertaining 
to thoughts in general, or true thoughts in general, rather than only to axioms in Frege's sense.

Even granted (1), the step to (2) is long: Frege emphasizes that he is concerned with Euclidean geometry in the letter to Liebmann and reemphasizes it in his words to Hilbert about "the doubt". Even granted (1) and (2), (3) is another shaky step. A disproportionate amount of Frege's complaining concerns Hilbert's misuse of "axiom". This is the specific complaint Frege voices at the end of the Jourdain notes when he refers to [28]. If the fact that the axiom of parallels is taken by Frege to be an axiom prompts his resistance in the Jourdain passage and [18], then his concerns, whatever they may be, need not carry over to the Desargues theorem or the Fundamental Theorem, which are not axioms in Frege's sense. So the one piece of direct textual evidence that is cited to support the thesis that Frege came to regard the sketch in [28] as unworkable fails to provide this support.

This paper set out to clear away some of the brush obscuring our view of Frege's metatheory of geometry. Frege's provocative and apparently uninformed remark has been shown to be principled, though badly expressed. Our next step should be to ascertain how the rest of the view appears once we have corrected this outlier.

\section{Notes}

This is the assessment of Freudenthal, one of the deans of the recent history of geometry. The high point of his remarks is: "Frege, rebuking Hilbert like a schoolboy, also joins the Boetians. (I have never understood why he is so highly esteemed today.)" ([31], p. 618) "Boetians" is, of course, an allusion to Gauss's famous remark that he suppressed his early research on non-Euclidean geometry out of a fear of the "fury of the Boetians". See also Boos [6].

More sympathetic to Frege's views are the valuable essays of Resnik [55] and Dummett [10]. Though I suppose I am closer to Resnik and Dummett in my attitudes to Frege's foundations of geometry than I am to Freudenthal and Boos, I do agree with the thrust of the complaint that Frege often really did fail to see what was important in what the people around him were doing. In particular, I completely agree with Boos (echoed in Ricketts [59]) that our sense of Frege's intellectual environment is significantly impoverished by the tendency among Frege scholars to rely apparently uncritically on Frege's own characterizations of the views of his opponents, without troubling to read the work of those opponents themselves. The result is a picture of Frege surrounded by drooling simpletons devoid of intellectual merit. It is crucial to remember that although Frege had many intellectual virtues, he was not without vices. One of them is displayed from time to time in Grundlagen [13], and degenerates to almost pathological levels as the years go by: Frege is a comically uncharitable reader of his opponents. In fact, Hankel, Kerry, Schubert, Korselt, and the rest had intelligent things to say. In some cases at least they were motivated to take the positions they did by concerns (like problems involved in counting the intersections of curves) that Frege never successfully addressed and that his account of number is particularly poorly placed to handle. (I have in mind particularly the-admittedly foggy, though mathematically astute-Hankel/Schubert reflections on "Conservation of Number/Permanence of Form." I discuss this point further in Tappenden [72].) 
2. There is also a "metatheme" to the paper which I will not be dwelling on, but which I will briefly make explicit here. Many aspects of Frege's philosophy will remain mysterious unless we learn more about his mathematical context. Naturally, to flesh out such a claim, specifics are needed, and this paper aims to contribute one narrow, tangible example. Indeed, the example is almost comically narrow: the interpretation of a single sentence is at stake. Read against the background of apparently widespread misconceptions about mathematics from 1870-1910, it can look as if Frege is rejecting independence arguments tout court. If the historical background is filled in this comes to be recognized as incredible.

Since anyone convinced by the first fifteen pages of this essay might regard the rest as overkill, I should make it clear that this second section should be read bearing in mind the folktale of the sons who produce year after year of bountiful grape harvests while tilling the fields for nonexistent treasure. It is the detail supporting the argument rather than the thesis that structures the argument that is the most interesting contribution of the negative part.

3. For brevity, I have restricted the account of the period from 1870 to 1906 to just what is absolutely necessary in the coming pages. An expanded account of these details of the mathematical context is in the other papers in this series (see [69], [70]).

4. The best known precursor of these ideas today is the renowned "Erlangen program" of Klein. When the relevant ideas of invariants as they show themselves in logic tend to be discussed today (Sher [67], Tarski [76]) this is the antecedent geometrical work that gets cited. But even though the EP was presented in 1872, it is unlikely that Frege would have known much about it until much later, and unlikely that he would have valued it as centrally as the Lie and Plücker work which informed it. (On the delayed reaction to the Erlangen program see Hawkins [34].) In saying that Frege would have been less familiar with the EP than with, say, Lie on contact transformations or the sphere mapping, I am not making a blanket pronouncement that includes all of Klein's work on transformations and invariants of discrete groups. Quite the contrary, I expect that Frege was thoroughly familiar with much of what Klein was up to in this domain. The point is directed only at the ambitious grand design of the EP which was less salient at the time than it appears in retrospect.

The Fregean connection with Plücker's geometry is suggested in Tappenden [75]. I develop them in further detail, along with the connections and parallels to Lie's work in [69].

5. Though I will not be dwelling on the point here, this generates yet another in a long list of problems for the Ricketts interpretation taken up in the later sections of this paper. Say we grant for the sake of argument that Frege did reject independence proofs in the period from at least the first letter to Hilbert onward, apart from a brief flirtation in 1906. (Also, of course, an inexplicable flirtation, given that Frege is alleged to have principled reasons stemming from deep, bedrock features of his philosophy for rejecting independence arguments.) Even if this is granted, which seems to me unlikely in the extreme, the fact that Frege openly accepts that the axioms of geometry can be shown independent generates hard problems for this view: did Frege change his mind about these purported deep features of his view, or did he fail to draw what was, on the Ricketts account, a quite obvious consequence of his own "universalism". Also Frege's stance in the Grundlagen [13] creates textual problems for the Ricketts interpretation: a significant fragment of the textual evidence he cites for his view comes from Grundlagen and the 
work written before. Given that Frege in that period clearly didn't reject independence arguments, that evidence becomes inadmissible.

6. Though Frege did not publish anything in geometry between 1884 and 1903, we can be sure he was engaged in and well informed about such research. In this connection we can draw on sources that include Frege's comments in correspondence, the work that appears in 1903 with Grundgesetze II (which, we can assume, was already well underway by 1900), the topics of Frege's lectures and other teaching, the record of his Nachlass, plus the work of the graduate students in his advanced classes and the research interests of his Jena colleagues. I spell this out in more detail in [69] and [70].

7. So, for example, he writes to Liebmann in 1900: "The independence of an axiom $A$ from others is a matter of the lack of contradiction between the contradictory of $A$ and the other axioms" ([23], p. 91).

8. A further complication worth noting is that there are two different preliminary copies of Frege's responses extant. They agree in most details, but the crucial "Jourdain sentence" occurs in only one; in the other the issue of indemonstrability is not touched at all (cf. Frege [17], p. 119).

9. A fourth point should be mentioned. Frege does not talk about the independence of the axiom of parallels from some other set of axioms but rather about its indemonstrability (full stop). This may be significant. But I don't think it is. As a matter of fact I think it is a red herring, and in my efforts at a positive interpretation I will set the point aside. My feeling is that Frege might have written "independent" (unabhängig), and this would have captured his intentions, but since Russell used the word "indemonstrability" in the passage Frege is commenting on, Frege wrote what he did using a close German equivalent instead. However, it is a demerit for my positive interpretation that I have to assume a certain looseness of usage on Frege's part. I will return to this point in the subsequent "negative interpretation" treatment of what I take it that Frege is not saying.

I am indebted to Paddy Blanchette for some discussions that helped me to get a clearer view of this issue.

10. In fact, only the weaker view that it is incoherent to suppose an axiom false is needed for the interpretation of the Jourdain sentence, but the textual evidence seems to point to Frege holding the strong view.

11. See also [21].

12. I consider Hilbert rather than Korselt since Korselt does make the natural concession of taking the sentences in the geometry to be interpreted sentences whose potential reinterpretations are studied. Hence Frege's objection to "mixing definitions and axioms" doesn't apply in its simplest form. I revisit this point later in the paper.

Here I am indebted to Boos [6] who took the step of actually reading what Korselt had to write, and found that Frege's representation of Korselt's discussion is an insulting caricature. This is, of course, just what one would expect, given the uncharitable and often scurrilous style the later Frege adopted toward his opponents.

13. Since I couldn't think of an English expression that would sit comfortably between "sentence" and "proposition" as the German "satz" does, I have elected to retain the translator's 
choice of "proposition" for "satz" though it sounds a bit odd to speak of a "proposition" expressing a thought.

14. Here I am in agreement with those who emphasize how the idea of recognition of the truth of a thought is the basis of Frege's account of inference. Unpublished work by Rumfitt and Jeshion has been most helpful to me on this point. The point that many of the oddseeming things Frege says in the [27] papers arise from the doctrine that inference must be from true sentences was observed early on by Resnik [55]. (Gabriel has drawn my attention to an even earlier article-Levinson [47] - in which this observation is made. $\mathrm{He}$ also noted that it was commonplace in the German Frege literature even earlier.)

15. Here I'll pause to explain a dialectical strategy that emerges from the dual focus of this paper. I want both to clarify the role of Frege's attitude to counterfactual assumptions in his foundations of geometry and to argue in particular that the Jourdain sentence is not a rejection of all independence arguments. For the interpretation of the Jourdain sentence, it is only necessary to work out Frege's attitude toward assuming axioms false. As it happens, Frege's attitude toward axioms seems to me to be prompted by a much stronger rejection of any counterfactual assumptions, except as the antecedents of material conditionals. Of course, it is always less risky to defend a weaker thesis (i.e., Frege thinks it is incoherent to posit that an evident truth is false) than a stronger one (Frege thinks it is incoherent to posit that a truth-evident or not-is false). To avoid leaving the impression that the interpretation of the Jourdain sentence depends on the stronger thesis, I have structured the discussion so that at crucial points I am discussing only Frege's attitude to assuming an axiom false. I hereby cancel the conversational implicature, that by discussing Frege's attitude toward axioms in particular, I think that his attitude holds only for axioms. The point of this restriction of focus is to assume only what is needed for the particular task at hand, not to suggest that only the weaker thesis is correct.

16. I am indebted to Levine [46] for drawing these Russell remarks to my attention and for reminding me of the Begriffschrifft position on modality. Also, I owe Levine a more formless debt of thanks for a fine article that served for me as a catalyst. I had been puzzling over Frege's views on reductio ad absurdum arguments for some time when a reading of that paper prompted several pieces to click into place.

So that my point should not be misunderstood, I should say explicitly that I take the fact that Russell and Moore had such views about modality to give at best the most distant and indirect evidence for Frege's views. In fact, I think that the differences in outlook, motives, and background dividing Frege and Russell are often drastically underestimated; the citation of Moore and Russell is meant just as a reminder that what we take to be obvious today about necessity has not always been so regarded.

17. That is, $A$ is "more necessary" than $B$ if $A$ has fewer logical consequences.

18. Not only is there the generic worry that there is always room to doubt whether such a possibly ancillary doctrine of Begriffsschrift, never mentioned again, is retained. A quite specific ground for reservations about the survival of the early doctrine is that the one change we do know took place between Frege's early and late doctrines - the bifurcation of content into sense and reference-seems like it could easily have induced a change in Frege's understanding of modality. If content includes both a truth-value and the thought expressed it might seem incoherent to suggest that a sentence might have that content but a different truth-value. This perceived incoherence might disappear if thought and truth-value are separated. 
19. There is a certain parting of the ways about the Jourdain sentence that is worth mentioning here. In a few pages it will be argued that in the Jourdain notes Frege is making a point about independence/indemonstrability in what he takes to be the generally accepted sense, not the revisionary defined sense of [28]. To this end, it is crucial to establish that Frege held these two definitions not to be equivalent. If late Frege did hold the same attitude toward modality as the Frege of 1879 , then he would have had at least this principled basis for treating the two definitions of independence to diverge.

Some writers - for example, Blanchette (in [4] and [3])—who take the Jourdain sentence to be a rejection of the independence test of [28], adopt no position on Frege's views on modality, so they have some room to maneuver. Ricketts seems committed to the view that the two definitions of independence must diverge for Frege given his understanding of Frege's views on modality:

Frege would not accept an appeal here to the possible circumstances under which a thought would be true, since modal notions play no basic role in his philosophy. Indeed, the very idea of the truth-conditions of a thought is foreign to Frege. (Ricketts [57], note 40, p. 187)

(Though I think that something close to the view Ricketts is proposing here is correct, I don't think that either reason he gives is compelling. The first is a shaky inference from "Frege doesn't say anything about $p . "$ to "Frege was committed to rejecting $p$. ." The latter rests on an account of Frege on truth that has been effectively criticized in Stanley [68]. See also my Tappenden [73].)

20. Ricketts also notes that Frege only allows inference from true premises and that his conception of consequence is in that way different from those we tend to study today (cf. [57], note 47, p. 188). The point here is that this difference between Frege's view and contemporary views also suffices to explain his twists and turns over the proper form for independence arguments.

21. Cf. [23], p. 16.

22. This source should be read with some reservations, as Frege didn't actually include this paragraph in the final version of the letter dated 28 January 1914 ([23], p. 81-84).

23. There may have been one other trace of this view that went lost. According to Scholz's record, a lost letter written in 1906-1907 from Husserl to Frege concerned "hypothetical structures" ([23], p. 70). The passages we are currently discussing seem to be the only topics in the extant writings and correspondance from about that time which would naturally answer to this label.

24. The case of Lotze has been extensively discussed-a good recent overview, with references to earlier discussions, is in Glock [32]. On Wundt and Trendelenburg the case is sparser. Frege refers to Wundt a few times-approvingly it appears. He refers once to Trendelenburg, and apparently adopts two distinctive words ('lingua characterica', 'begriffsschrift') from him. Also there is some-though as usual maddeningly inconclusive-evidence that Frege had a good working relationship with his Jena colleague Eucken, who was somewhat of a champion of Trendelenburg's virtues. (Gabriel informs me that from his window-he lives in what was once Eucken's Jena homeyou can see across the street to the nearby house where Frege lived.) On Eucken on Trendelenburg (see [12], pp. 111-25). On Bolzano see note 21. 
In addition, Wilson in England endorsed and took over Lotze's negative view of indirect proof, though this is of course far from Frege's turf. (cf. the posthumously published Wilson [81], p. 553-60)

Here the evidence is the Nachlass record of a 17-page notebook full of notes, titled “'Logic von Dr. Christoph Sigwart' Tübingen 1873” (cf. Veraart [79], p. 103) (I am indebted to Picardi [52] for drawing this catalog record to my attention.)

26. Here again, Mancosu has identified several helpful parallels on the mathematical side, including Hölder and Hessenburg. Among mathematicians the most tantalizing for our purposes is Löwenheim. (Mancosu also discusses Löwenheim [48], though I had hit on that parallel independently.) Löwenheim carried on an extended (19 letter) correspondence with Frege in the years 1908-1910 on the topic of the acceptability of formalist theories. Also Löwenheim regarded indirect proofs (understood to be proofs in which an assumption is made that is subsequently found to be false) as suspect, redeemable only if translatable into a direct proof (for example, through contraposition). But once again the evidence is crucially incomplete: [48] is undated, and it may well not reflect the views he held in 1908-1910. Worse, the correspondence itself was lost in the bombing of the Münster library. All we know is that the correspondence existed, and that (according to the original archivist Scholz) it dealt with an attempt by Löwenheim to convince Frege that a viable formalist account of theories could be obtained from developing Frege's remarks in Grundgesetze II $\$ 90$. (Scholz also says that over the course of these letters Löwenheim convinced Frege of this position, but, well, caveat emptor.) (cf. Scholz and Bachmann [63]).

So what we end up with is a weak observation, but still one worth making: the suggestion that there might be something amiss about indirect proofs was an ambient feature of Frege's intellectual setting. We shouldn't be misled by the fact that most contemporary writers are indifferent to the topic regarding it as idiosyncratic for Frege to adopt the strong stand he seems to say he does.

27. With Bolzano though, the case is thin at the places that are crucial here. The best basis for attributing some knowledge of Bolzano (before 1906) to Frege is the series of essays by Kerry: "Anschauung und ihr Psychische Verarbeitung" in Vierteljahrsschrift für Wissenschaftliche Philosophie. Of course, we can be sure Frege read some of the essays in the series, since he responds to them in print, and it isn't unreasonable to assume that he would have been at least passingly familiar with them all. The series contains what is probably the most extensive discussion of Frege's work to make it into print before 1900. Kerry takes up a wide range of issues in Frege's writings along with those of many others. Wound in with the discussion of Frege is an extensive, sympathetic presentation of Bolzano's doctrines, including mention of Bolzano's views of reductio arguments. (cf. Kerry [38], pp. 117-18). Unfortunately, the view of inference as proceeding from truths to truths as the basis for the attitude toward reductio arguments are two features of Bolzano's writings that are not, so far as I have been able to ascertain, touched on in Kerry's essays. Of course, it isn't inconceivable that the summaries of Bolzano's views in Kerry's essays might have prompted Frege to go out and read Bolzano's writings for himself, but obviously that can't be assumed.

Later, in 1908-too late to influence the 1906 sketch, but early enough to influence the Jourdain remarks and [18]-Korselt sketched the basic details of Bolzano's theory of consequence in [43]. Frege never mentions this essay in print, though an offprint of the article and a page of notes in Frege's hand were in his Nachlass (cf. [79], p. 100). But the 
fact that for Bolzano, inference always proceeds from truths to truths was not given any stress in the 1908 Korselt article, and so Frege might not have picked up on the affinity.

28. Since I have found that the point of the sort of detail presented here can be wildly misconstrued if filtered through a principle of uncharity, it is perhaps worth repeating that the point here is not "Frege must have believed $P$ because he read Lotze and Lotze believed $P$ " (or Wundt, or Trendelenburg. . . ). Though this kind of detail is useful to flesh out the context, its role in the argument here is narrowly restricted and "defensive." Frege states his view explicitly and that is the evidence I am basing my reading on; the need for defensive retrenchment arises because the view Frege states might seem so odd to a contemporary reader that one might be inclined to look for alternate interpretations of what Frege plainly says. The ancillary contextual detail is meant as a counterweight to that sense of antecedent implausibility that may be felt when confronting an option that is currently no longer thought to be a live one.

29. When Frege remarks that a repeated failure to come up with a contradiction could well lead one to have confidence that the axiom was unprovable, he was describing the situation that, as he well knew, actually obtained. Long before Beltrami and Klein developed the precursors of contemporary independence arguments there was a long series of highprofile (and many low-profile) failed attempts to deduce a contradiction from the negation of the axiom of parallels. Frege certainly knew all this. He would have expected his audience to treat it as common knowledge too. This gives an indirect significance to this remark: "If, however, we went on drawing inference after inference and still did not come up against a contradiction anywhere, we should certainly become more and more inclined to regard the axiom as incapable of proof." (I take it that Frege is implying that it would be reasonable to come to the conclusion that a proof was not possible, though what he says could also be interpreted as merely a descriptive claim about our psychological tendencies.)

This was a fairly widespread view about what the previous centuries of failed proof attempts entail. For example, in a 1906 historical survey, Bonola echoes Frege's remarks, in reference to the actual history:

The very fact that the innumerable attempts made to obtain a proof did not lead to the wished-for result, would suggest the thought that its demonstration is impossible . . But such considerations cannot be held to afford a proof of the impossibility in question. (Bonola [5], p. 177)

This ties into a point on which Ricketts and I agree, which is the core theme of Tappenden [71]. Frege clearly has in his repertoire the idea that plausible arguments can lend support to mathematical and logical theses even in cases where they have not been proven. (Though the point that failed efforts in the past can make it plausible that the efforts couldn't have succeeded does nothing to support the further claim that Ricketts needs, which is that such plausible argument is the only kind available.)

30. To completely take in the similarity, it is worth the time to read the two passages side by side.

31. Also, though I have given the point little attention here, the unexplained changes in Frege's view from Grundlagen to "Foundations of Geometry I/II" (the newly expressed doubts about independence in geometry, the disappearance of "conceptual thought") turn out to arise naturally from another change that Frege explicitly announces: the bifurcation of "(conceptual) content" into "thought" and "truth-value". 
In addition to the misgiving, I also regret an incompleteness of the picture as a whole. (This incompleteness, though a source of regret, does not threaten the key features that the preceding interpretation has built on.) What is missing is an account of the source of Frege's reluctance to consider the negation of an axiom. There are several possibilities, each of which has some textual support. (The possibilities are not mutually exclusiveFrege may have held them all.) Since I will not be building anything on the specific details, I'll just list the possibilities and gesture at the support for them before moving on:

1. For Frege, inference is a matter of inferring from sentences that are known. When one understands an axiom, one sees immediately that it is true, on Frege's account. So, merely understanding the negation of an axiom is also recognizing that the negated axiom is not true. It therefore cannot be known, or even thought to be known, and hence cannot be the premise of an inference. Personally I am inclined to think of this as the most likely of these possibilities and the most fertile soil for further tilling. Rumfitt is currently at work on an account of Frege's views of logic that takes off from the observation that for Frege, inference is inference from known premises.

2. Frege upholds a strong rejection of counterfactual reasoning about thoughts: If a thought is in fact true, it is incoherent to ask what would be the case if it were false. I do think that Frege held this, possibly because he took it to be a consequence of (1). I think the evidence that Frege did hold this view is very good but not so strong that it would be unreasonable to hold something else.

3. Frege retains throughout his writings the epistemic view of necessity and possibility that he states in Begriffsschrift. An axiom is necessary in this sense and its negation is not possible. So, Frege might have reasoned, it is incoherent to consider "what would happen if this impossible claim were true?" (This seems to me the least promising of the options. In particular, I am unsure how to reconcile the suggestion that Frege held this view of modality throughout his career and that he applied the view of modality to independence questions in this way with his talk about "conceptual thought" in Grundlagen [13].)

33. Another writer who takes the sentence in the Jourdain notes to point immediately to the conclusion that Frege was rejecting the 1906 sketch is Blanchette in [3]. The discussion here could be taken to be a response to her article as well, on this narrow point of interpretation. Blanchette's background position (foreshadowed in the illuminating article [4]) is importantly different from that of Ricketts, however. While my disagreement with Ricketts over the interpretation of the Jourdain sentence arises from a general disagreement on a wide range of details of Frege's interpretation, my disagreement with Blanchette is quite local. For the most part, I think that her view is not only generally correct, but indeed quite illuminating and important. Blanchette's key observation, it seems to me, is that once Frege introduced "thoughts" as the primary bearers of logical relations he also created an extra task for himself. There is a gap between the symbols we use to write proofs and the thoughts whose relations are displayed by these proofs. Blanchette takes Frege to have a principled objection to independence proofs arising from this gap. She takes Frege to have held that it cannot be conclusively proven that a given system of symbols is a perfect "mirror" (Frege's expression) of the logical relations of a given system of thoughts. Hence, on this interpretation, no "independence argument" dealing with a specific language can be a conclusive demonstration of the logical relations of dependence and independence among thoughts because it couldn't be ruled out that the actual logical relations among the thoughts were not adequately reflected in the grammar and syntax of the language studied. 
Apart from our understandings of the Jourdain sentence, Blanchette and I diverge just on this point: I don't think Frege held that one couldn't be certain that a given language was an adequate "mirror" of the logical relations. I agree that Frege thought there was a gap, but it seems to me that one overall thrust of the sequence of late Logical Investigations essays (Frege [30], [26], [25]), and the unpublished fragmentary continuation Frege [19], is precisely to bridge it. Here Frege aims to nail down the details of the structure of thoughts so that the syntax of a language can be devised to "mirror" them. The basic thought-language connections corresponding to the logical connectives and quantifiers are hammered out, and presumably recognized as evident; the rest of the arguments can be carried out by familiar inductive means, with no special problems posed by the need to use the syntax of symbols to reflect the logical properties of thoughts.

34. As a testament to the entrenchment of this reading of Frege, it suffices to look to the forthcoming Cambridge Companion to Frege [56]; over half of the contributors are proponents of one form or another of the "no metatheory" view.

5. In a session of the June 2000 ASL summer meetings in Urbana-Champaign in which some of this material was presented, plus some work of Blanchette supporting similar conclusions, Goldfarb objected that the mere fact that, for Frege, false sentences have no consequences is enough to show that Frege didn't have a conception of logical consequence as we currently conceive it. (His only other defense was the "Frege lacks a conception of logical law" point taken up in note 37.) If this is all the "no metatheory" position amounts to-for Frege, false sentences have no consequences and we have a more inclusive view of consequence - then I agree completely with the view so understood, and so does every other Frege scholar including Dummett, the favored target in writings of the "no metatheory" school. This feature of Frege's conception of inference has been recognized and acknowledged by everyone for decades. Note though, that Frege's rejecting "logical consequence" in this sense is in no way incompatible with his viewing independence arguments to be possible.

However, it would be a Pyrrhic victory to hold ground through such simple literalness. As the example of independence arguments illustrates, the resulting differences between Frege and us are too meager to support the broad, ambitious methodological conclusions that the proponents of the "no metatheory" view generally take to flow from their interpretation. In [73], I discuss in further detail the general phenomenon that most of the appearance of substance in the "no metatheory" interpretations arises from playing on ambiguities between defensible but uninteresting positions and interesting but completely indefensible ones (with arguments provided for the former and conclusions drawn from the latter).

36. Even on its own terms, though, this move is inadequate to the position it is supposed to support: "Appearances notwithstanding . . . Frege's 1906 foray into metalogic confirms the Dreben-van Heijenoort interpretation" (pp. 2-3, emphasis added). Even if we grant (what seems to me unlikely in the extreme) that Ricketts is right on all matters of detail, and that Frege did take the [28] ideas to be a "dead end," this does not support the Drebenvan Heijenoort thesis as Ricketts presents it, for two reasons. (The response is implicit in my discussion of the [28] sketch in [73].) First, on Ricketts's view, Frege has reasons of principle arising from his conception of logic for rejecting his explorations in [28]. But even if Frege did make efforts to flesh out the [28] sketch and abandon the project, it could well have been because he found the details unwieldy or unduly complicated. [28] certainly seems to be written as if Frege's worries are at most worries that the details might turn out to be technically unworkable. On Ricketts's reading, we have to accept 
that Frege wrote with caution in [28] because he was already convinced, in 1906, of a principled objection which automatically and straightforwardly ruled that sketch as incapable of completion. Yet Frege doesn't breathe a word of this principled objection, or say anything that could plausibly be taken to be an indirect allusion to it. Second, to the extent that Frege has reservations, they concern only the sketched principles for independence proofs. He shows no reservation at all about the earlier discussion of soundness. So even if the specific details were to fall Ricketts's way, the [28] sketch so interpreted wouldn't buttress the "no metatheory" picture very well.

. Ricketts cites only these reasons to support his view:

1. He states: "This very clarity [that Frege attains] makes it noteworthy that Frege in his extensive subsequent writings about logic and thoughts does not return to the semantics of the 1906 paper." ([58], p. 185)

2. Ricketts draws some support from a speculative interpretation of Frege's attitude toward the mathematical character of his proposed new basic law.

3. Ricketts reads Frege as having what Ricketts (following van Heijenoort) calls an "experimental" conception of the completeness of a given formulation of logic, independence of one axiom from others, and so on, as supportable only by probable argument.

4. Ricketts suggests—-both implausibly and irrelevantly—-that Frege "doesn't have a notion of logical law" (as noted in note 37, this was reiterated by his close collaborator Goldfarb);

5. The Jourdain sentence.

I take up (1), (2), and (3) in other papers; my objective in this paper is to address (5).

The issues raised by (2) are sufficiently complex to require a separate treatment, which I try to provide in [69] and [70]. In this note I'll gesture toward parts of my responses to points (1), (3), and (4), which are discussed at greater length in [69] and [71], respectively. I will address (4) in this note as well: the treatment if it can be brief for now, until more details are forthcoming from Ricketts.

On (3): First of all, Frege does often say, as he should, that some arguments only provide probable support for mathematical and logical conclusions. However, none of the passages where Frege says this even hint that he thinks that the conclusions at issue can only be given probable support. Occasionally Frege even explicitly denies this. Second, it is quite misleading to apply Herbrand's expression "experimental" to the arguments that Frege calls "probable". Frege's explicit epistemological position is that there are different "sources of knowledge"- the logical source, the geometric source, and empirical sources. A key question on this picture is "What is the source of our probable reasoning about logical and arithmetical conclusions?" Ricketts's overall view seems to push him to hold, as the terminology suggests, that the knowledge he calls "experimental" must be nonlogical. But it is likely that Frege thought the probable reasoning in this case is a species of logical knowledge, grounded in the "logical source". Frege says little on the subject of probable reasoning, but what he does say suggests that he shares the broadly neo-Kantian views about the laws underwriting empirical prediction held by his precursors Apelt, Fries, and his "revered teacher" Snell, as well as (though in slightly different forms) his Jena colleague Liebmann and his teacher Lotze. (One variant way to put the point, quite anachronistically for orientation, is that Frege was a "logicist" about probability, in the manner of his contemporary von Kries, his (broadly speaking) student Carnap, Keynes, and (at least one of the low rungs of the ladder on) the Tractatus. Frege would not likely have held that an argument would be nonlogical simply because it had an only probable conclusion, if it appealed to no empirical truths as data.) The issue 
of the logical and mathematical constraints on observation was in fact an astonishingly thoroughly discussed one in Jena at the time, which makes it more likely that the remarks Frege makes on induction and observation indicate thought-out views. I discuss this aspect of Frege's mathematical environment in more detail in [70].

On (1), I think three points are relevant. Briefly: (a) It is misleading to say that Frege's writings after 1906 are "extensive." Frege actually writes very little besides the Logical Investigations essays, especially if it is remembered that [18] is a set of lecture notes. For well over ten years after the sequence of 1903-1906 played out, Frege never managed to sustain even a single paper. This is what one would expect given that that period saw the Russell paradox, whose breach in the lifelong program of Grundgesetze quickly came to seem irreparable, the death of Frege's wife after a long illness, the death of Frege's teacher, supporter, and dear friend Abbe, and the complete rancorous collapse of what appears to have been a good working relationship with Frege's senior colleague Thomae. (A presumably happier event, but still potentially disruptive and distracting to research, as any parent knows, was the adoption of little Alfred by widower Frege.) Frege gave every indication of being intellectually in despair, starting and revising jotted notes about what could be salvaged from his work. It is hard to accept that any lacunae in this dark period should have any probative value. Furthermore, (b) it would be child's play to compile a long list of obviously crucial topics for Frege that are never again mentioned after 1906. It is hard to see that such an absence, even if there were one, would support any conclusions at all. (c) The one thing that Frege does write and publish after 1906 is the Logical Investigations sequence, which is directly relevant to the sketch in [28] since it lays out the connections between the structure of thoughts and the structure of a logical language.

On (4) I will be brief, since Ricketts's point has not been sufficiently developed to support a detailed response. There is far more to say on the subject, but this should suffice to indicate just how enormous the problems facing the Ricketts-Goldfarb point is. Taking just the core observation as it has been articulated, the "Frege believed there could be no general criterion of a logical law" point fails at a surprising number of different levels. It fails textually in that there is no reason to believe it is true of Frege, and it fails dialectically in that even if Frege lacked a notion of logical law, the consequences Ricketts tries to draw for Frege's philosophy overall simply don't follow even in watered-down forms.

It is, of course, true that Frege doesn't actually state an adequate criterion of logical lawhood. This complaint was lodged already by Kerry in 1889, and (let's face it) this was a just complaint. But for Ricketts's point to even have a hope of holding water, it must be that Frege thought it impossible in principle to find such a criterion. (Otherwise the only bar to the independence proof would be that someone hadn't figured the criterion out yet, which is hardly a deep philosophical roadblock.) Not only is there zero textual evidence for Frege believing this, but it seems antecedently quite unlikely and it makes much of what he says in the [28] sketch incomprehensible.

(Ricketts does give one argument, though it is hard not to regard it as a sign of desperation. He appeals to the fact that many of the terms needed for one possible Fregean definition of logical law can be argued to be vague. This is beside the point, as what Ricketts and Goldfarb need is that Frege recognized that by his standards the notion of logical law is vague, which seems unlikely on its face and completely without textual evidence.

Of course, such a maneuver might work to foist onto Frege a commitment to this view, given his criteria of sharp boundaries plus the simple fact that by Frege's standards everything is vague, even the concept of number, or the concept of course-of-values in Grundgesetze. The vagueness of virtually every concept is recognized by every Frege 
scholar as a point which can completely undermine Frege's entire enterprise. The fact that Frege carried on with his project despite the fact that his sharp boundaries criterion would serve as the aqua regia of the entire enterprise suggests that, in fact, he didn't push the point as far as this. But really, if it is just a commitment to this position that we want, we could have obtained it much more easily by arguing that since Frege was committed to Basic Law V, he was committed to a contradiction, and hence he was committed to everything, and therefore he was committed to rejecting independence arguments. This would give us the desired conclusion too, and it would be every bit as relevant as the conclusion in the form Ricketts obtains it.)

But say we grant this unlikely textual claim for the moment. Say that Frege believed that one couldn't in principle have a criterion for "logical law" and furthermore that an explicated version of "logical law" (with any borderline cases stipulated away) couldn't be taken as a notion that was primitive and undefinable but still acceptable for theoretical use. Even so Frege could still prove independence in the specified sense so long as he had in fact a complete list of the logical laws. Frege not only thinks that is possible, but in fact a requirement of reason: "[Kant's view] conflicts with one of the requirements of reason, which must be able to embrace all first principles in a survey" ([13], p. 6). Again Ricketts has not developed his point enough to indicate why this wouldn't be enough for an independence proof. (Though perhaps this fanciful option might lead to a scenario where one could prove independence, but not prove one had proven it.)

A last concern is worth mentioning. Even if we grant all of these unlikely possibilities, it remains possible for Frege to accept an argument in which it was shown that one couldn't derive the geometric axiom using some specified list of logical laws and axioms relative to some given set of primitives. Rickett's sole response appears to be this: “. . . moreover, it seems Frege finds no point to proving independence with respect to some precisely demarcated fragment of logic; and purely syntactic results about the underivability of a formula within a particular formalism hold no interest for him" ([57], p. 184).

Of course, if Frege has no interest in this sort of thing, he is an almost pathologically incurious fellow, something the Ricketts interpretation regularly requires him to be. But even if he were uninterested, that would be irrelevant; that Frege has no interest in a question is light-years away from what is needed here, which is that Frege is committed to regarding the question as intrinsically pointless.

It is worth noting explicitly that the Ricketts argument in general is in even more trouble than the above remarks indicate since the above remarks are narrowly addressed to the question of independence arguments. Frege also sketches other metatheoretic arguments, such as soundness arguments, in [28]. For Ricketts's interpretation of Frege on metatheory and the truth-predicate, Frege must be rejecting those too. But even if, per impossible, Ricketts's arguments to the effect that Frege rejected the sketch of independence proofs were cogent, it would give no reason to think that Frege rejected the soundness arguments. It would at best affect only independence and completeness arguments. Given that in these soundness arguments Frege is using the truth-predicate in a way that even Ricketts grants is incompatible with his view of the truth-predicate, the interpretation of Frege on the truth-predicate, and the interpretation as a whole, is again in desperate straits.

38. This will be only part of the story. In other work ([69], [70]) I consider the 1906 sketch itself in its mathematical context to bring out how naturally it emerges from a family of geometric questions that were a matter of ongoing concern for Frege. These studies have the side effect of making the idea that it was hedged because of worries about "metatheory", or a principled "mathematics/philosophy" distinction even more implausible. Here I am narrowly addressing the textual evidence-the Jourdain sentence itself. 
39. This seems even more likely if we recall that Frege might take special exception to the suggestion that the axiom of parallels was indemonstrable simpliciter. As Frege was surely aware, ever since the publication of well-known and startling essays by Riemann and Helmholz in the late 1860s the suggestion that the parallels axiom might be a contingent empirical claim had had its proponents. This was, for example, maintained by Erdmann in his 1877 Axiome der Geometrie Erdmann [11] to which Frege refers in Grundlagen [13].

40. Before considering the interpretation itself, it is important to see how it softens the force of any suggestion that we should read Frege with absolute strictness in what he says in the Jourdain sentence. If we do that, we still don't get a rejection of the 1906 sketch, we get this reading. To get a rejection of the 1906 sketch we have to assume that Frege spoke loosely (by omitting reference to the specific system of axioms from which the axiom of parallels was to be independent) but not loosely in the way I am suggesting. That is, it must be argued that Frege's usage must be read as precise enough to rule out the equation of "indemonstrable" and "independent" but not so precise as to rule out the equation of "indemonstrable" with "indemonstrable from the remaining axioms of Euclidean geometry".

One reason I find it hard to accept the possibility that Frege takes axioms to be intrinsically demonstrable is that Frege says repeatedly that axioms and basic laws "neither need nor admit of proof" ([28], p. 295, [13], and so on). On the other hand, in 1914, in [18] he maintains that whether or not something is an axiom is a system-relative matter, which may indicate a softening of this stance: a thought which is an axiom (in one system) can be proven (in a different system). Something like this is indicated by Frege's using the expression "Axiom of Archimedes" for a principle that he proves in Grundgesetze II.

Perhaps Frege means that his favored formulation of the parallel postulate could be proven in a system which took, say, Playfair's postulate as an axiom. There will be no shortage of evident truths that are equivalent to the axiom of parallels but which differ in sense from it.

A second problem for this line - the one I find more persuasive-is that Frege does seem to be fairly sanguine about the possibility that the axiom of parallels is in fact indemonstrable: note his remark in [18] about what we might conclude from the many years of failed proof attempts. His complaints in [18] seem to rest not with the independence (in the 1906 sense of: unavailability of a demonstration) of the axiom, but rather with the possibility of giving proofs of independence (in the pre-1906 sense of "the possibility that the negation of the given axiom could be true").

41. This picture of Frege as caught off guard by the mathematical content of Hilbert's arguments seems to show itself in Ricketts's discussion when, for example, he describes Frege as "[greeting] Hilbert's claim to have proved the independence of the parallel postulate from the other Euclidean axioms with astonished incredulity . . Frege struggles in his [27] and even more in [28] to make sense of Hilbert's mathematical achievement" ([57], p. 179).

Only on an armchair caricature of the actual historical events could "astonished incredulity" at Hilbert's "mathematical achievement" appear to be what Frege is venting with his fulminations. The mathematical content was not a surprise.

So far as the axiom of parallels in particular is concerned, the work of Hilbert almost thirty years later refined the point in various ways that will be considered in later sections, but the basic point is taken to be present already in Klein. This is also how Klein's results 
were regarded at the time, at least by most. So, for example, here is how Klein himself sums up his discovery at the end of [40]:

The examination of non-Euclidean geometry is in no way intended to decide the validity of the parallel axiom but only to address this question: Is the parallel axiom a mathematical consequence (eine mathematische Folge) of the other axioms of Euclid? To this question these investigations provide a definite no. ([40], p. 314)

Die Untersuchungen der Nicht-Euklidischen Geometrie haben durchaus nicht den Zweck, über die Gültigkeit des Parallelenaxioms zu entscheiden, sondern es handelt sich in denselben nur um die Frage: of das Parallelenaxiom eine mathematische Folge der übrigen bei Euklid aufgeführten Axiome ist; Ein Frage, die durch die fraglichen Untersuchungen definitiv mit Nein beantwortet wird.

As I pointed out in [75], it was during Frege's time as a graduate student in Göttingen that the three key essays Klein [39], Cayley [7], and Klein [40] appeared in the Göttingenbased journal founded and edited by Frege's teacher Clebsch. It is unlikely in the extreme that Frege wasn't familiar with these articles. The point was widely discussed even by philosophers. So, for example, as early as 1880, in a book we know Frege to have read (he cites it several times; see [75], note 19), Wundt speaks of the work of Klein as establishing "the independence of the parallels axiom from the remaining axioms of geometry (die Unabhängigkeit des Parallelenaxioms von den übrigen Axiomen der Geometrie)" (Wundt [82], p. 442). Klein is also described this way in [11] which Frege cites. This, of course, doesn't tell us what Frege thought about the arguments, but it does clarify what he would have taken to be "common coin" in the mathematical community.

Klein's original presentations needed significant corrections, as Freudenthal gleefully points out ([31], pp. 614-15; see Rowe [61] for some details). As I mention in the next section, there may still have been questions in the air, though most details had been resolved by that time. However, none of these could be prompting Frege's response to Hilbert in particular: Hilbert explicitly draws all the mathematical content of his argument for the axiom of parallels from what went before. Any complaints Frege might have had about earlier independence arguments would have been carried over whole.

2. By 1906, of course, Hilbert had produced more relevant material, at least some of which Frege read but Frege continued to address his remarks to the Gauss-Weber Festschrift treatment, so I'll continue to look to it as containing the relevant Hilbert view. Frege had also, by this time, (cf. [23], p. 43, 49) read at least Hilbert's "mathematical problems" lecture, the handwritten "Elements of Euclidean Geometry," and a lecture that was the basis for "Über den Zahlbegriff" (Hilbert [37]) but none of these has anything different from Hilbert [37] in ways that appear to matter here.

43. I have taken the translation from [36], p. 32. This early translation is a rendering of a manuscript which is essentially the same as [35]. There are some alterations, but the original of the quote given here and the neighborhood around it are identical. That is, in the work Frege read, Hilbert devotes only one, remarkably casual paragraph to the axiom of parallels - a paragraph in which, furthermore, all he does is gesture in the direction of other work. This cursoriness has proved to be easily overlooked by some Frege scholars, because the treatment is expanded to several pages in subsequent editions. (It is a translation of the later, tenth edition that Ricketts cites, for example.) In scholarly work in this area, it is crucial to remember that the Hilbert Grundlagen der Geometrie was treated in practice as a work in progress. Each edition contained new material 
and corrections to the old. Even after Hilbert's death his assistant Bernays remained at the grindstone. French translations often were revised yet again from the German originals. By the tenth German edition-which the English translation currently in print is a translation of-things are very different indeed.

44. For the geometric background to Hilbert's foundations, from a philosophical point of view, see Hallett [33].

45. Another way to put this is: given three distinct points $A, B, C$ on a line $l$, and four distinct points $A^{\prime} B^{\prime} C^{\prime} D^{\prime}$ on another line $l^{\prime}$, if the points $A, B, C$ are projectively related the fourth point $D$ on $l$ corresponding to $D^{\prime}$ under this projection is uniquely determined.

46. I say Frege was sure to have seen this article, or at least known of its contents, for the following reasons. Frege's activities in geometry were generally in this area, so he would have a general interest, and the article was in fact quite widely influential. The article appeared in the Jahresbericht der Deutschen Mathematiker-Veireinigung, a journal edited by Frege's Jena colleague Gutzmer. Frege apparently discussed Hilbert's foundations with Gutzmer, as he refers to conversations with him in letters to Hilbert and Liebmann ([23], p. 34, p. 91). The $J D M-V$ was (not coincidentally) the place where [27] and [28] were published, in 1903 and 1906, respectively. Presumably Gutzmer would have discussed the content of Frege's work with him prior to publication of the article and would have drawn Frege's attention to evidently relevant prior work in the same journal. Also, since Frege discussed these issues with Thomae, it is worth noting that the 1894 textbook issuing from Thomae's Jena lectures on the pure projective treatment of conics contains extended reflections about what principles might be needed to prove which others, mentioning Weiner's article explicitly (cf. [77], pp. 24-25). Frege would have to have been familiar with this book and the contents of the lectures not just because he spoke with Thomae, but also because his students would have been attending the lectures and using the book. The subject of projective methods and conic sections constitutes or overlaps significantly with the contents of Frege's summer semester exercises of 1890, 1891, 1894, 1895, 1900, 1901, and 1904 (cf. Thomae's records of the seminar for the corresponding years), and (judging by the titles) his classroom lectures of 1894, 1900, and 1904 (cf. Kratzsch [44]).

47. Schur also emphasizes this point in his textbook [64]. Both Schur and Hilbert, following then current German nomenclature, write of "Pascal's Theorem" for what is usually called "Pappus's theorem" by English writers. (What English writers call "Pascal's theorem" is there called "Pascal's theorem for conics".)

48. I discuss this in more detail in [75] and [69]. As a further indication, the first of a regular series of lecture courses Frege offered at Jena entitled "Analytic Geometry according to the Newer Methods" appears to have involved almost exclusively projective techniques: identifying the cross-ratio, working out the useful projective invariants, and so on (cf. [17], p. 347-64). To appreciate the course title, it is important to recall that during these years "Neuerne Geometrie" was essentially a term of art, meaning "Geometry exploiting projective methods".

49. Cayley uses "descriptive" to mean what we currently would mean by "projective". 
50. Here is a simple formulation of the Archimedean axiom: if $a>0$ and $b>0$ are numbers [segments] then there is some number of times one can add $a$ to itself so that $a+a+\cdots+a>b$.

51. In one of these lectures, delivered in January of 1880, Frege studied combinatorial patterns generated by collections of points, finally generating a collection representing the Desargues theorem (Frege [16], pp. 384-87). In the abstract, Frege calls the Desargues theorem "the Theorem on Perspective Triangles", but his statement of the theorem and the diagram make it clear that this is merely a difference in nomenclature. In the other, delivered in January 1881, Frege observes that a given system of four points in projective geometry allows one to develop a metric (this is one guise of the Fundamental Theorem). Also relevant here is the Pascal/Brianchon duality that Frege explored in the 1891/92 summer seminar. This fundamental duality example is the extension of the Pappus theorem to curves of second order.

52. Cf. Frege [14], (pp. 204-6). See also the discussion in Dummett et al. [9], pp. 288-90. The connection between commutativity and Hilbert's foundations of geometry is also emphasized in [37].

53. I am leaving aside a further possibility arising from some Fregean remarks that suggest a tight connection between the sense of "(Euclidean) straight line" and the parallels axiom. From his thesis to his late fragments Frege holds geometrical knowledge to be founded on intuition, or some special "geometrical source". However, his later discussion of the parallels axiom also indicates that he counts the sense of the axiom of parallels to be bound up with our knowledge of the parallels axiom in a crucial way. Recall the quote given above:

Can the axiom of parallels be acknowledged as an axiom in this ["the traditional"] sense? When a straight line intersects one of two parallel lines, does it always intersect the other? This question, strictly speaking, is one that each person can only answer for himself. I can only say: so long as I understand the words 'straight line', 'parallel', and 'intersect' as I do, I cannot but accept the parallels axiom. If someone else does not accept it, I can only assume that he understands these words differently. Their sense is indissolubly bound up with the axiom of parallels. ([18], p. 247)

For more on this possibility, see Demopoulos [8].

54. In a letter of 1900 to Liebmann "I have reasons for believing that the independence of the axioms of Euclidean geometry cannot be proved" ([23], p. 91, Frege's emphasis); see also ([23], p. 38, p. 44) where in letters to Hilbert he speaks of "a doubt" in a way that could be taken to indicate that the doubt pertains to Euclidean geometry only. (That reading is hardly forced, though.)

55. For more detail, see [69] and [70]. I regret that it is hard to economically state the point of this subsection without relying on a distinction between "mathematical" and "philosophical" investigation that seems to me to collapse under close examination. But I hope I will be forgiven the use of the distinction as an approximate one for preliminary orientation.

56. And, the interpreter of the picture might continue: since the mathematics was completely in order as it stood, who really needed the philosophy? This popularity of this widespread 
quietism seems to me to arise from a misapprehension of the relation between mathematics and philosophy among those working "on the border."

57. Even setting aside issues of the strict correctness of proofs, there are issues of diagnosis, or "mathematical taste" that can arise. I explore this in further detail in [69]. Frege in the [28] sketch took substitution-invariants as a key idea in his approach, and there was a significant emerging mathematical tradition that was of one mind with him. (Frege doesn't mention groups, let alone Lie groups, but as I argue in [69] he would have known that this is one place that fleshing out his sketch would take him.) Poincaré made a close cousin of this complaint in his generally highly laudatory review of Hilbert's Grundlagen, complaining that he was puzzled why Hilbert would disguise ("dissimuler") the role of Lie groups and invariance (cf. Poincaré [54]). In fact, one of the most illuminating alternatives to Hilbert's approach developed this theme. (Though this thread leads far from anything Frege did or contemplated, it is worth mentioning both for its own sake and as a further counterweight to an overly simple "Hilbert the mathematician/Frege the philosopher" contrast.) Schwan [66] developed a group-theoretic interpretation of the calculus of line segments that forms the basis of Hilbert's foundations. An affine variation on the theme, worked out by Artin, was developed into a powerful and revealing analysis of geometry in the classic Artin [1]. Hilbert's foundations was a landmark in mathematical history, but Frege's sketched alternative is not without its own complementary mathematical virtues. (Though to be sure, these virtues are present only "as a tree is present in its seeds."). I am indebted to Howard Stein for drawing my attention to Schwan's anticipation of Artin's analysis.

58. As one cautionary tale testifying to the intricacy of the history, I should soften a point I mentioned in Tappenden [74] (pp. 324-25) that according to Klein [41] and in Klein's notes to his collected papers, many people around him suggested that his development of non-Euclidean geometry from projective geometry contains a "vicious circle". Klein mentions Ball and Cayley in particular, but suggests that the complaint was widespread. This has become a reasonably widely cited historical detail. (To name just two citations of many see Rowe [60] and Birkhoff and Bennett [2].)

But I may have been rash. My impression, from my own investigations and from talking to historians of mathematics familiar with this area is that the veracity of Klein's recollections should be downgraded to "open question." It's not clear that this attitude was widespread at all. After extensive combing, the only people I have encountered in print making the complaint are Ball and Cayley, and Cayley seems to be going along with Ball a bit grudgingly. (Land [45] makes a complaint about curved space which is distantly similar to Ball's complaint, but he doesn't mention Klein.) Here I am especially indebted to Rowe, Gray, Hawkins, and Richards for extensive and patient responses to vague email questions.

59. On Hilbert's continuity assumptions, see [61]. I am indebted to Pedoe ([51], p. xii) for the observation about Hilbert's "Pappus implies Desargues" proof. Since this topic has been raised, it is perhaps worth adding one more thing - if only as a check against a too sanguine view of mathematical activity as it occurs "in nature." According to the list compiled by Pickert [53] and [51] (whose word I'm inclined to accept on this point), this theorem has been blessed with at least nine erroneous proofs in its short history. 


\section{References}

[1] Artin, E., Geometric Algebra, Interscience Publishers, Inc., New York, 1957. MR 18,553e. 309

[2] Birkhoff, G., and Bennett, M., "Felix Klein and his 'Erlanger Programm',” pp. 145-76 in History and Philosophy of Modern Mathematics, edited by P. Kitcher and W. Aspray, University of Minnesota Press, Minneapolis, 1988. MR 89b:00023. 309

[3] Blanchette, P., "Frege's metatheory and the 1906 independence-test," Manuscript. 297, 300

[4] Blanchette, P. A., "Frege and Hilbert on consistency," The Journal of Philosophy, vol. 93 (1996), pp. 317-36. MR 98g:03004. 297, 300

[5] Bonola, R., Non-Euclidean Geometry. A Critical and Historical Study of its Development, Dover, Mineola, 1955. English translation by H. Carslaw; Italian original published 1906. 299

[6] Boos, W., “' 'The true' in Gottlob Frege's 'Über die Grundlagen der Geometrie'," Archive for History of the Exact Sciences, vol. 34 (1985), pp. 141-92. 293, 295

[7] Cayley, A., "On the non-Euclidean geometry," Mathematische Annalen, vol. 5 (1872), pp. 630-34. 306

[8] Demopoulos, W., "Frege, Hilbert, and the conceptual structure of model theory," History and Philosophy of Logic, vol. 15 (1994), pp. 211-25. MR 95i:03003. 308

[9] Dummett, M., S. Adeleke, and P. Neumann, “On a question of Frege's about right-ordered groups," pp. 53-64 in Frege and Other Philosophers, Clarendon Press, Oxford, 1991. 308

[10] Dummett, M., "Frege on the consistency of mathematical theories," pp. 229-42 in Studien zu Frege. Band I, Frommann-Holzboog, Stuttgart, 1976. MR 58:21379. 293

[11] Erdmann, B., Die Axiome der Geometrie. Eine Philosophische Untersuchung der Riemann-Helmholzschen Raumtheorie, Leopold Voss, Leipzig, 1877. 305, 306

[12] Eucken, R., “Zur Erinnerung an Adolf Trendelenburg," pp. 111-25 in Beiträge zur Einführung in die Geschichte der Philosophie, Verlag der Dürr'schen Buchhandlung, Leipzig, 1906.

[13] Frege, G., Grundlagen der Arithmetik, W. Koebner, Breslau, 1884. English translation by J. L. Austin, The Foundations of Arithmetic: A Logico-Mathematical Enquiry into the Concept of Number, Northwestern University Press, Evanston, 1980. 273, 279, 283, 285, 293, 294, 300, 304, 305

[14] Frege, G., Grundgesetze der Arithmetik, vol. 2, H. Pohle, Jena, 1903. 308

[15] Frege, G., "Begriffsschrift: A formula language modeled on that of arithmetic, for pure thought," pp. 1-82 in From Frege to Gödel, edited by J. van Heijenoort, Harvard University Press, Cambridge, 1967. 279

[16] Frege, G., Nachgelassene Schriften und wissenschaftlicher Briefwechsel. Band I: Nachgelassene Schriften, edited by H. Hermes, F. Kambartel, and F. Kaulbach, Felix Meiner Verlag, Hamburg, 1969. MR 42:1640. 308 
AXIOMS, INDIRECT PROOF, AND INDEPENDENCE ARGUMENTS 311

[17] Frege, G., Nachgelassene Schriften und wissenschaftlicher Briefwechsel. Band II: Wissenschaftlicher Briefwechsel, 2d edition, edited by G. Gabriel, H. Hermes, F. Kambartel, C. Thiel, and A. Veraart, Felix Meiner Verlag, Hamburg, 1976. MR 58:27146. 295, 307

[18] Frege, G., "Logic in mathematics," pp. 203-50 in Posthumous Writings, edited by H. Hermes, F. Kambartel, and F. Kaulbach, Basil Blackwell, Oxford, 1979. 276, 277, 280 , 281, 283, 284, 285, 293, 298, 303, 305, 308

[19] Frege, G., "Logical generality," pp. 258-62 in Posthumous Writings, edited by H. Hermes, F. Kambartel, and F. Kaulbach, Basil Blackwell, Oxford, 1979. 301

[20] Frege, G., "A new attempt at a foundation for arithmetic," pp. 278-81 in Posthumous Writings, edited by H. Hermes, F. Kambartel, and F. Kaulbach, Basil Blackwell, Oxford, 1979.

[21] Frege, G., “On Euclidean geometry," pp. 167-69 in Posthumous Writings, edited by H. Hermes, F. Kambartel, and F. Kaulbach, Basil Blackwell, Oxford, 1979. 276, 295

[22] Frege, G., "Sources of knowledge of mathematics and the mathematical natural sciences," pp. 267-74 in Posthumous Writings, edited by H. Hermes, F. Kambartel, and Kaulbach F., Basil Blackwell, Oxford, 1979. 276

[23] Frege, G., Philosophical and Mathematical Correspondence, edited by G. Gabriel et al., University of Chicago Press, Chicago, 1980. Translated from the German by H. Kaal with an appendix by P. E. B. Jourdain. MR 81d:03001. 272, 273, 275, 276, 280, 290, 295, 297, 306, 307, 308

[24] Frege, G., "Formal theories of arithmetic," pp. 112-21 in Collected Papers on Mathematics, Logic and Philosophy, edited by B. McGuinness, Basil Blackwell, Oxford, 1984. 272

[25] Frege, G., "Logical investigations, Part III: Compound thoughts," pp. 390-406 in Collected Papers on Mathematics, Logic and Philosophy, edited by B. McGuinness, Basil Blackwell, Oxford, 1984. Beiträge zur Philosophie des deutschen Idealismus, III (1923). 301

[26] Frege, G., “Negation: A logical investigation,” pp. 373-89 in Collected Papers on Mathematics, Logic and Philosophy, edited by B. McGuinness, Basil Blackwell, Oxford, 1984. Beiträge zur Philosophie des deutschen Idealismus, I (1918).

[27] Frege, G., "On the foundations of geometry: First series," pp. 272-84 in Collected Papers on Mathematics, Logic and Philosophy, edited by B. McGuinness, Basil Blackwell, Oxford, 1984. 272, 296, 305, 307

[28] Frege, G., "On the foundations of geometry: Second series," pp. 293-340 in Collected Papers on Mathematics, Logic and Philosophy, edited by B. McGuinness, Basil Blackwell, Oxford, 1984. 272, 274, 276, 277, 278, 283, 284, 285, 286, 287, 288, 291, 293, 297, 301, 302, 303, 304, 305, 307, 309

[29] Frege, G., "Review of Gall and Winter: Die Analytische Geometrie des Punktes und der Geraden und Ihre Anwendung auf Aufgaben," pp. 95-97 in Collected Papers on Mathematics, Logic and Philosophy, edited by B. McGuinness, Basil Blackwell, Oxford, 1984.

[30] Frege, G., “The thought: A logical investigation," pp. 58-77 in Collected Papers on Mathematics, Logic and Philosophy, edited by B. McGuinness, Basil Blackwell, Oxford, 1984. Beiträge zur Philosophie des deutschen Idealismus, I (1918). 
[31] Freudenthal, H., "The main trends in the foundations of geometry in the nineteenth century," pp. 613-21 in Logic, Methodology and Philosophy of Science, edited by E. Nagel, P. Suppes, and A. Tarski, Stanford University Press, Stanford, 1962. 293, 306

[32] Glock, H. J., “Vorsprung durch Logik: the German analytic tradition,” pp. 137-66 in Royal Institute of Philosophy Supplement, Cambridge University Press, Cambridge, 1999.

[33] Hallett, M., "Hilbert on geometry, number, and continuity," Manuscript. 307

[34] Hawkins, T., "The Erlanger Programme of Felix Klein: Reflections on its place in the history of mathematics," Historia Mathematica, vol. 11 (1984), pp. 442-70. 294

[35] Hilbert, D., "Die Grundlagen der Geometrie," pp. 1-92 in Festschrift zur Feier der Enthüllung der Gauss-Weber-Denkmals in Göttingen, Teubner, Leipzig, 1899. 287, 288, 290, 306, 312

[36] Hilbert, D., Foundations of Geometry, The Open Court Publishing Company, Chicago, 1902. Translation of a minor revision of [35]. 277, 306

[37] Hilbert, D., "On the concept of number," pp. 1089-95 in From Kant to Hilbert: A Sourcebook in the Foundations of Mathematics, Oxford University Press, Oxford, 1996. Original Über den Zahlbegriff published 1900. 306, 308

[38] Kerry, B., “Anschauung und ihr psychische Verarbeitung," Vierteljahrsschrift für Wissenschaftliche Philosophie, vol. 16 (1889), pp. 71-124. 298

[39] Klein, F., "Über die Sogennannte nicht-Euclidische Geometrie,” Mathematische Annalen, vol. 4 (1871), pp. 573-625. 306

[40] Klein, F., "Über die Sogennannte nicht-Euclidische Geometrie,” Mathematische Annalen, vol. 6 (1873), pp. 112-45. 289, 306

[41] Klein, F., Development of Mathematics in the Nineteenth Century, volume 9 of Lie Groups: History, Frontiers and Applications, Math Science Press, Brookline, 1979. Translated by M. Ackermann. 309

[42] Korselt, A., "Über die Grundlagen der Geometrie," Jahresbericht der Deutschen Mathematiker-Veireinigung, vol. 12 (1903), pp. 402-7.

[43] Korselt, A., "Über die Logik der Geometrie," Jahresbericht der Deutschen MathematikerVeireinigung, vol. 17 (1908), pp. 98-124. 282, 298

[44] Kratzsch, I., "Material zu Leben und Wirken Freges aus dem Besitz der Universitätsbibliothek Jena," pp. 534-46 in Begriffsschrift-Jenaer Frege Konferenz, Friedrich-Schiller Universität, Jena, 1979. 307

[45] Land, J. P., “Kant's space and modern mathematics," Mind, vol. 2 (1877), pp. 38-46. 309

[46] Levine, J., "Logic and truth in Frege," Proceedings of the Aristotelian Society, (1997), pp. 141-75. Supplementary volume. 296

[47] Levinson, A., "Frege on proof," Philosophy and Phenomenological Research, vol. 22 (1961/1962), pp. 40-49. 296 
AXIOMS, INDIRECT PROOF, AND INDEPENDENCE ARGUMENTS 313

[48] Löwenheim, L., “On making indirect proofs direct,” Scripta Mathematica, vol. 12 (1946), pp. 125-39. MR 8,307h. 298

[49] Moore, G., “Necessity,” Mind, vol. 9 (1900), pp. 289-304. 279

[50] Pasch, M., Vorlesungen über neuere Geometrie, BG Teubner, Leipzig, 1882. 282

[51] Pedoe, D., An Introduction to Projective Geometry, Pergamon Press, Oxford, 1963. MR 33:600. 309

[52] Picardi, E., "The logics of Frege's contemporaries," pp. 173-204 in Speculative Grammar, Universal Grammar, and Philosophical Analysis of Language, edited by D. Buzzetti and M. Ferriani, John Benjamins, Amsterdam, 1987. 298

[53] Pickert, X., Projektiven Ebenen, Springer, Berlin, 1955. 309

[54] Poincaré, H., "Review of Hilbert's foundations of geometry," Bulletin of the American Mathematical Society, vol. 10 (1903), pp. 1-23. Translated by E. Huntington. 309

[55] Resnik, M., "The Frege-Hilbert controversy," Philosophy and Phenomenological Research, vol. 24 (1974), pp. 386-403. 293, 296

[56] Ricketts, T., Cambridge Companion to Frege, forthcoming. 301

[57] Ricketts, T., "Frege's 1906 foray into metalogic," Philosophical Topics, vol. 25 (1997), pp. 169-88. 297, 304, 305

[58] Ricketts, T., "Logic and truth in Frege," Proceedings of the Aristotelian Society, (1997), pp. 121-40. Supplementary volume. 286, 287, 302

[59] Ricketts, T., “Truth-values and courses-of-value in Frege's Grundgesetze," pp. 187-212 in Early Analytic Philosophy, edited by W. Tait, Open Court Publishing, Peru, 1997. 293

[60] Rowe, D. E., "Klein, Hilbert, and the Göttingen mathematical tradition," Osiris. A Research Journal Devoted to the History of Science and its Cultural Influences. Second Series, vol. 5 (1989), pp. 186-213. MR 92b:01047. 309

[61] Rowe, D. E., "Perspective on Hilbert," Perspectives on Science. Historical, Philosophical, Social, vol. 5 (1997), pp. 533-70. MR 2000b:01022. 306, 309

[62] Russell, B., Principles of Mathematics, Cambridge University Press, Cambridge, 1903. 279

[63] Scholz, H., and F. Bachmann, "Der Wissenschaftliche Nachlass der Gottlob Frege," pp. 24-30 in Actes du Congré s International de Philosophie Scientifique VII: Histoire de la Logique ou de la Philosophie Scientifique, Sorbonne, Paris, 1935. 298

[64] Schur, F., Lehrbuch der analytischen Geometrie, Veit and Company, Leipzig, 1898. 307

[65] Schur, F., "Über den Fundamentalsatz der projectiven Geometrie," Mathematische Annalen, vol. 51 (1899), pp. 401-9. 289

[66] Schwan, W., "Streckenrechnung und Gruppentheorie," Mathematische Zeitschrift, vol. 3 (1919), pp. 11-28. 309

[67] Sher, G., The Bounds of Logic: A Generalized Viewpoint, The MIT Press, Cambridge, 1991. 294 
[68] Stanley, J., "Truth and metatheory in Frege," Pacific Philosophical Quarterly, vol. 77 (1996), pp. 45-70. 297

[69] Tappenden, J., "Geometrical invariance and mathematical practice in Frege," Manuscript. 288, 294, 295, 302, 304, 307, 308, 309

[70] Tappenden, J., "Logical dependence and mathematical practice in Frege's Foundations of Geometry,” Manuscript. 289, 294, 295, 302, 303, 304, 308

[71] Tappenden, J., "Probable reasoning and 'fruitful concepts' in mathematics: further Fregean themes," In preparation. 299, 302

[72] Tappenden, J., "Simplicity, ontology, and counting: Some complications," In preparation. 293

[73] Tappenden, J., "Metatheory and mathematical practice in Frege," Philosophical Topics, vol. 25 (1997), pp. 213-64. 297, 301

[74] Tappenden, J., "Extending knowledge and "fruitful concepts": Fregean themes in the Foundations of Mathematics," Noûs, vol. 29 (1995), pp. 427-67. MR 97a:00016. 309

[75] Tappenden, J., "Geometry and generality in Frege's Philosophy of Arithmetic," Synthese, vol. 102 (1995), pp. 319-61. MR 96h:03012. 294, 306, 307

[76] Tarski, A., "What are logical notions?" History and Philosophy of Logic, vol. 7 (1986), pp. 143-54. MR 88b:03010. 294

[77] Thomae, J., Die Kegelschnitte in rein Projectiver Behandlung, Louis Nebert, Halle, 1894. 290, 307

[78] Toepell, M.-M., Über die Entstehung von David Hilbert's “Grundlagen der Geometrie”, Vandenhoeck and Ruprecht, Göttingen, 1986. MR 88d:01026. 289, 290

[79] Veraart, A., “Geschichte des Wissenschaftlichen Nachlassen Gottlob Freges und seiner Edition: Mit einem Katalog des ursprünglichen Bestands der nachgelassenen Schriften Freges," pp. 49-106 in Studien zu Frege/Studies on Frege, edited by M. Schirn, FromannHolzboog, Stuttgart-Bad Cannstatt, 1976. 298

[80] Weiner, H., “Über Grundlagen und Aufbau der Geometrie,” Jahresbericht der Deutschen Mathematiker-Veireinigung, vol. 1 (1891), pp. 45-48. 289

[81] Wilson, J. C., Statement and Inference, edited by A. Farquharson, Oxford University Press, Oxford, 1926. 298

[82] Wundt, W., Logik. Eine Untersuchung der Principien der Erkenntniss und der Methoden Wissenschaftlicher Forschung, volume 1, Ferdinand Enke, Stuttgart, 1880. 306

\section{Acknowledgments}

This paper is a replacement for the one given at the conference: the paper from which the original talk was given grew to far more than journal length. The present paper is a contribution to the same project of spelling out in detail how Frege's philosophical work represents a rational response to diverse threads in his mathematical environment 
AXIOMS, INDIRECT PROOF, AND INDEPENDENCE ARGUMENTS 315

(and his intellectual environment more broadly.) I am indebted to Ali Behboud, Patricia Blanchette, Mic Detlefsen, Gottfried Gabriel, Michael Hallett, David Hills, P. J. Ivanhoe, James Joyce, Ian Proops, Michael Resnik, Larry Sklar, and Rich Thomason for conversations and comments. Several discussions with Aldo Antonelli and Bob May about their paper in this volume were helpful to me; their paper itself serves as an excellent companion to this one. Michael Scanlon was especially generous with written comments on an earlier draft. Long before I started thinking seriously about the Frege-Hilbert correspondence, I had many illuminating conversations with Susan Sterrett, which taught me a great deal about Frege, about Hilbert, and about mathematics. Susan also shared with me her unpublished papers, "Hilbert and Frege on the Foundations of Geometry" (1994) and "Frege on Hilbert's Foundations of Geometry," (manuscript of talk presented at Pittsburgh Graduate Students' Philosophy Colloquium, October 1994). Many years ago I heard Michael Hallett give a terrific lecture on the mathematical background to Hilbert's foundations of geometry, and I have been urging him to get it out to a broader audience ever since. I believe that most of the specific observations I make here were arrived at independently, but it is not easy to be sure. (Occasionally I have thought I discovered the significance of something on my own only to discover it already there in the text of Michael's talk. (For example the relation of Hilbert's discovery of the connection between Desargues theorem and embedding in three dimensions).) Irrespective of matters of detail, the general effect on my sense of the richness of the issues here and on my overall orientation was significant. I first heard the "Jourdain sentence" cited as evidence that Frege had not trusted the 1906 sketch in a seminar by Burton Dreben at Boston University in 1995, and I had some useful discussions with him at that time. Thanks also to Juliet Floyd.

Department of Philosophy

University of Michigan

2228 Angell Hall

Ann Arbor MI 48104

tappen@umich.edu

http://www-personal.umich.edu/ tappen 